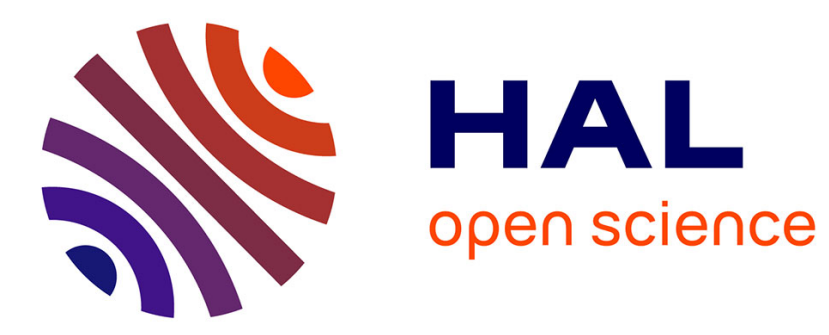

\title{
Denominal affixes as sources of antipassive markers in Japhug Rgyalrong
}

\author{
Guillaume Jacques
}

\section{To cite this version:}

Guillaume Jacques. Denominal affixes as sources of antipassive markers in Japhug Rgyalrong. Lingua, 2014, 138, pp.1-22. 10.1016/j.lingua.2013.09.011 . halshs-01244876

\section{HAL Id: halshs-01244876 \\ https://shs.hal.science/halshs-01244876}

Submitted on 16 Dec 2015

HAL is a multi-disciplinary open access archive for the deposit and dissemination of scientific research documents, whether they are published or not. The documents may come from teaching and research institutions in France or abroad, or from public or private research centers.
L'archive ouverte pluridisciplinaire HAL, est destinée au dépôt et à la diffusion de documents scientifiques de niveau recherche, publiés ou non, émanant des établissements d'enseignement et de recherche français ou étrangers, des laboratoires publics ou privés. 


\title{
Denominal affixes as sources of antipassive markers in Japhug Rgyalrong*
}

\author{
Guillaume JACQUES
}

December 16, 2015

\begin{abstract}
In this paper, we review the documented diachronic pathways leading to antipassive markers in the world's languages and show that Japhug Rgyalrong, a polysynthetic language belonging to the Sino-Tibetan family, attests a previously unreported source of antipassives.

In Japhug, the two antipassive constructions (human and non-human antipassive) are built from the base verb through a two-step process: first nominalization into an action nominal, and second denominal verbalizing derivation of the action noun into an intransitive verb. Nominalization neutralizes the verb's transitivity, and a new transitivity value is allocated by the denominal prefix.

A similar pathway is proposed for other derivations, in particular the applicative.

Keywords: Antipassive, applicative, causative, denominal verbs, nominalization, action nominalls, Rgyalrong, Japhug, Nahuatl, Eskaleut, Grammaticalization
\end{abstract}

\section{Introduction}

The diachronic origin of antipassive markers, unlike that of passive markers and constructions (for instance Haspelmath 1990), has only attracted a limited amount of scholarship. ${ }^{1}$ This lack of research is due in part to the fact that antipassive constructions are less common than passive ones cross-linguistically, but also that many constructions that could have been

\footnotetext{
"I wish to thank Evangelia Adamou, Denis Creissels, Bernd Heine, Nathan W. Hill, Katarzyna Janic, Aimée Lahaussois, Sergey Say and two anonymous reviewers for useful comments on previous versions of this article. This research was funded by the $\mathrm{Hi}$ malCo project (ANR-12-CORP-0006) and is related to the research strand LR-4.11 Automatic paradigm generation and language description of the Labex EFL (funded by the ANR/CGI). Glosses follow the Leipzig glossing rules, except for ASSERT assertive, CONST constative, LNK linker and INV inverse.

${ }^{1}$ To my knowledge, Say (2008: 99-375) is the only reference discussing this topic in a typological perspective.
} 
described as antipassives are usually described with a different terminology, especially in languages whose flagging is aligned accusatively.

Antipassives are overtly marked intransitivizing constructions that demote the patient of transitive verbs, whereby the agent of the original verb (A) becomes the only argument (S) of the verb in the antipassive construction; the demoted $\mathrm{O}$ either receives oblique case or is deleted from the construction. This definition allows for constructions variously labelled as 'depatientive', 'detransitive', 'deaccusative' or 'deobjective' in accusative languages ${ }^{2}$ to be designated as antipassive, following authors such as Heath 1976, Polinsky (2011) and Creissels (2012), but excludes agent-preserving lability and incorporation.

Previous work has pointed out five cross-linguistic origins for antipassive markers, presented in the following table: ${ }^{3}$

Table 1: Attested sources of antipassive markers

\begin{tabular}{|c|c|c|}
\hline origin & example & reference \\
\hline \multirow[t]{3}{*}{ reflexive } & Slavic, Romance, & Nedjalkov (2007), Say (2008: 378-517) \\
\hline & West Mande, & Creissels (2012) \\
\hline & Pama-Nyungan & Terrill (1997) \\
\hline \multirow{3}{*}{$\begin{array}{l}\text { benefactive / malefactive } \\
\text { reciprocal / coparticipation } \\
\text { indefinite, generic argument }\end{array}$} & Eskaleut & Jacobson (1984: 453), Mithun (2000: 97-8) \\
\hline & Tswana & Creissels and Nouguier-Voisin (2008) \\
\hline & Nahuatl & Langacker (1977: 46) \\
\hline non-telic & Godoberi & Tatevosov (2004) \\
\hline MAKE & West Mande, Eskaleut & Creissels (2012) \\
\hline GET & Eskaleut & Fortescue (1996) \\
\hline
\end{tabular}

The first three origins can involve the intermediate stage of a middle construction. Nominal origins (such as BODY) are well-attested for reflexive, reciprocal and middle markers (Heine and Kuteva 2002: 58), but no such case has been reported for antipassive constructions.

The last pathway, namely derivation from antipassive periphrases with the verb 'make' or 'get', has only been described for two groups of languages: Eskaleut and Mande.

In West Greenlandic, we find three antipassive ('half-transitive') suffixes: -(s)i-, -nnig-and -ller- ${ }^{4}$ According to Fortescue (1996), all three suffixes originate from the combination of nominalizing or participial suffixes with a postbase (bound stem):

- $-(s) i$ - results from the fusion of the passive participle *-ðaR with the postbase *-li 'to make, to become' (Fortescue et al. 2010: 438, 447).

\footnotetext{
${ }^{2}$ See Janic (2013) for a review of the terminology used to refer to antipassive constructions in accusative languages. Some authors restrict the definition of antipassive constructions to ergative languages (for instance Dixon 1994 and Cooreman 1994).

${ }^{3}$ A detailed account of the Nahuatl antipassive is provided in section 4.3.

${ }^{4}$ Mithun (2000: 97-8) mentions antipassives deriving from benefactive markers in Yup'ik, but these are not related to the Greenlandic suffixes.
} 
The change of proto-Eskimo $* \partial$ - to Greenlandic $s$ - is regular.

- $-n n i g$ - comes from the fusion of the nominalizer * $-n \partial R$ with the verb * $-n \partial \gamma^{\prime}$ 'to get' (Fortescue et al. 2010: 457, 459).

- -ller- originates from a nominalizer (which could be either the nominalizer *-łәь- or the passive participle *-kas-) combined with the postbase *-loy 'to provide with' (Fortescue et al. (2010: 451, 442, 459))

In West Mande, Creissels (2012) similarly argues that the antipassive suffixes $-n d i$ in Soninke originate from a verb root that can be reconstructed as *tin 'to do', and that the antipassive construction in question comes from a periphrase comparable to French acheter ('to buy', transitive) $\Rightarrow$ faire des achats ('to do shopping', with the verb faire 'to do').

In this paper, we present a related, but slightly different, pathway of grammaticalization of the antipassive in Japhug, a polysynthetic Sino-Tibetan language spoken in Sichuan, China. Like the Greenlandic case, it involves two steps: nominalization of a transitive verb and then denominal derivation back into a verb. An important difference of the Japhug case from both Eskaleut and West Mande is that denominal derivational prefixes cannot be etymologically derived from a verb. ${ }^{5}$

This paper is divided into four sections. First, we present background information on Japhug in general, in particular on nominalization and transitivity. Second, we offer an account of the antipassive construction in Japhug and discuss all the derivational prefixes homophonous with the antipassive prefixes. Third, we provide arguments showing that one of the two antipassive prefixes originates from a denominal construction. Fourth, we show that a similar scenario can be proposed to explain the origin of the applicative marker.

\section{Background information}

Japhug Rgyalrong is a polysynthetic language belonging to the Sino-Tibetan family, spoken by fewer than 10000 speakers in Mbarkhams county, Rngaba district, Western Sichuan, China.

The closest relatives of Japhug are the other Rgyalrong languages: Situ, Tshobdun, and Showu. The distribution of the four Rgyalrong languages is indicated in Figure 1; the black dot represents the Japhug speaking area.

Like other Rgyalrong languages, Japhug presents a very rich system of prefixal voice derivation, including causative, applicative, passive, anticausative, antipassive (Jacques 2012b) and incorporation (Jacques 2012c); transitive verbs agree with two arguments in person and number.

\footnotetext{
${ }^{5}$ This issue will be discussed in more detail in 4 .
} 


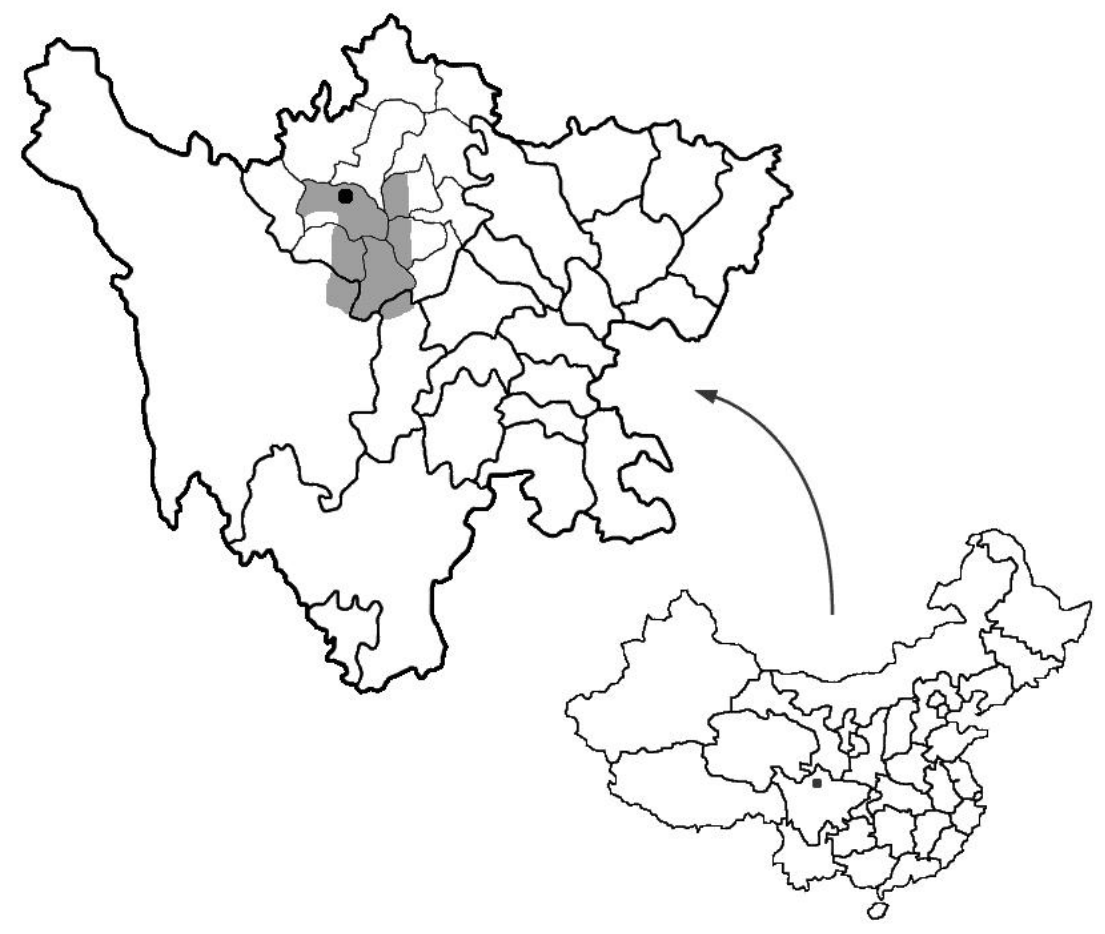

Figure 1: Rgyalrong languages

In this section, we present all background information needed to follow the argumentation: transitivity marking in Japhug, nominal morphology and nominalization. Antipassive derivation in Japhug is described in more detail in section 3 . We will in particular discuss the fact that no less than four different $t u$ - prefixes are found in nouns, a topic that will be of importance for our diachronic hypothesis in section 4.

\subsection{Nominal morphology}

As the present article will discuss the derivation of verbs from nouns, some information on nominal morphology is necessary. Three features of nouns are described here: possession and number.

The main morphological feature of Japhug nouns is possession. Nouns can be divided into two main categories: inalienably and alienably possessed nouns. ${ }^{6}$ Inalienably possessed nouns require a possessive prefix in all cases, while alienably possessed nouns may or may not have such a prefix.

\footnotetext{
${ }^{6}$ This terminology follows works such as Thompson (1996) on Athabaskan languages; see also Sun (1998) on the related Tshobdun language.
} 
Inalienably possessed nouns must either bear one of the possessive prefixes in Table 2. The indefinite possessive prefix has two variants tu- and $t \gamma$ - whose distribution is lexically determined. Alienably possessed nouns can take the prefixes in Table 2, but not the indefinite possessive prefix.

Table 2: Pronouns and possessive prefixes

\begin{tabular}{|c|c|c|}
\hline Free pronoun & Prefix & Person \\
\hline aदo, $r j$ & $a-$ & $1 \mathrm{SG}$ \\
\hline$n \gamma z o, n \gamma j$ & $n \gamma-$ & $2 S G$ \\
\hline шъо & $u-$ & $3 S G$ \\
\hline tढizo & $t \epsilon i-$ & 1DU \\
\hline ndżizo & $n d \not z i-$ & 2DU \\
\hline zrni & $n d \not z i-$ & 3DU \\
\hline izo, izora, izrra & $i-$ & $1 \mathrm{PL}$ \\
\hline пшъо, пиъога, пшъъта & nu- & 2PL \\
\hline zara & nu- & 3PL \\
\hline tüदo & $t u-$ or $t \gamma-/ t a-$ & indefinite / generic \\
\hline
\end{tabular}

In this paper, inalienably possessed nouns will be cited by their root form with a hyphen indicating the obligatory presence of a possessive prefix. Thus -jab 'hand' implies that the form *jab on its own is not possible for the meaning 'hand', and one will either find the indefinite form tu-jas 'someone's hand' or a form with a possessive prefix such as a-jas 'my hand', $n \gamma$-jas 'your hand' etc.

Inalienably possessed nouns ( 1 and 2 ) can be converted to alienably possessed by adding a possessive prefix before the indefinite possessor (example 3).

(1) uI-sruI

3SG.POSS-horn

Its horn

(2) ta-sru

INDEF.POSS-horn

A horn

(3) u-ta-sruu

3SG.POSS-INDEF.POSS-horn

His horn (the horn taken from an animal)

This phenomenon is not restricted to Rgyalrong languages, but also found in other languages with possessive affixes, such as Athabaskan. ${ }^{7}$

\footnotetext{
${ }^{7}$ For instance in Navajo we find a similar opposition between si-tsi' 1sG.POSs-flesh 'my
} 
Aside from possessive prefixes, an important morphological category occurring in the nominal domain are the numeral prefixes of quantifier nouns (Table 3; only numerals up to 10 are indicated, but all numerals up to one hundred can occur as prefixes). These nouns include measure of time (tur-xpa 'one year' etc), of length (tur-tya 'one handspan' etc), various quantities ( $t u-y d r t^{\prime}$ 'one section' etc) or classifiers ( $t u-r d o b^{\prime}$ 'one piece' etc).

Table 3: Numerals and numeral prefixes in Japhug

\begin{tabular}{|c|c|c|}
\hline & Numeral & prefix \\
\hline 1 & $c i$ & $t u-$ \\
\hline 2 & впит & БกUU- \\
\hline 3 & $\chi$ sum & $\chi S U I-$ \\
\hline 4 & kußde & kußßde- \\
\hline 5 & kumрu & kumpıu- \\
\hline 6 & kutşr- & kuts $\gamma$ \\
\hline 7 & кшьпит & kuьппu- \\
\hline 8 & kurcat & kurcy- \\
\hline 9 & kungut & kungu- \\
\hline 10 & $s q i$ & squI- \\
\hline
\end{tabular}

Although the numeral prefix tur-is formally similar to the indefinite possessor tu-, the two are entirely distinct, as they alternate within different paradigms (respectively Tables 2 and 3). It is not possible to add both series of prefixes on the same quantifier noun. Non-quantifier nouns cannot receive numeral prefixes.

Numeral prefixes are obligatory with quantifier nouns. The only exception is observed with measures of time: the numeral prefixes can be replaced with the third person possessive $u$ - to express the meaning 'that (particular) year', 'that day' etc, as in example 4.

(4) пu u-хра taxpa maka mr-pe tu-ti-nu DEM 3sG.POSS-year harvest at.all NEG-NPST:good IPF-say-PL

'People say that the harvest is not good in a year like that.' (Lhamtshams.32)

No other possessive prefix may be used with these measure nouns.

flesh' and she-'a-tsi' 1sG.POSS-INDEF.POSS-flesh. 'my meat (bought at the marker)' (Young and Morgan 1987: 10). The theoretical implications of this phenomenon go beyond this paper. 


\subsection{Nominalization}

Japhug Rgyalrong, like other Rgyalrong languages (see for instance Sun 2003 on the Tshobdun language), has a very rich system of nominalization prefixes. Four different prefixes are productive: the S/A nominalization $k u-$, the $\mathrm{O}$ nominalization $k \gamma$-, the oblique nominalization $s \gamma$-and the action nominalization $t u-$. This section will briefly describe the first three, then describe the prefix tu- and prefixless nominalized forms in more detail, as the latter two will be more relevant to our diachronic hypothesis in section 4.

\subsubsection{Argument and adjunct nominals}

The nominalized forms derived with the three first prefixes $k u-, k \gamma-$ and $s \gamma$ - are fully productive, and can be used to build relative clauses (Jacques 2004: 464-9). The S/A nominalization prefix $k u-$ appears with both intransitive and transitive verbs, but in the latter case a possessive prefix (from Table 2) coreferent with the patient is added (see 6). This nominalized form can be used as one of the tests to determine whether a particular verb is transitive or intransitive (cf section 2.3)

(5) $\quad$ ku-si

NMLZ:S/A-die

'The dead one'.

(6) ul-kut-sat

3SG-NMLZ:S/A-kill

'The one who kills him.'

The nominalization prefix kut- has two irregular forms $\gamma$ - or $x$ - which can be found in a few nouns (Table 4). Most of these nouns are possessed nouns, but mainly occur with the third person singular possessive $u-$.

\begin{tabular}{|c|c|c|c|}
\hline noun & meaning & base verb & meaning \\
\hline$\gamma n d z \gamma \beta$ & disastrous fire & $n d z \gamma \beta$ & burn \\
\hline -улав & disaster & лав & be black \\
\hline -Удһш & orifice & лғиш & be opened \\
\hline$-\mathrm{XSO}$ & empty thing & so & be empty \\
\hline
\end{tabular}

The semantic relationship between the base verb and the derived nouns in Table 4 is not entirely obvious synchronically, as the nouns have undergone an independent semantic evolution. The changes from $/ \mathrm{k} / \mathrm{\gamma} / \mathrm{y} /$ and 
$/ \mathrm{k} / \rightarrow / \mathrm{x} /$ on the other hand are perfectly regular in Japhug; the phonological irregularity lies in the loss of the vowel only.

As the first element of a cluster in Japhug, stops only occur before the non-nasal sonorants $/ \mathrm{r} /, / \mathrm{j} /, / \mathrm{w} /, / \mathrm{l} /$ and $/ \mathrm{\gamma} / .^{8}$

This gap in the distribution of velar and labial is accounted for if we take into consideration the fact that clusters with velar or labial fricatives as their first element in Japhug always correspond to clusters with velar or labial stops in the closely related Situ language (Jacques 2004: 270; for instance, $-x t \gamma \gamma$ 'brother' corresponds to Situ Rgyalrong -kték), which suggests that as the first element of clusters, stops have undergone fricativisation in Japhug.

Since the language disallows clusters of the type stop + nasal as well as stop $+\mathrm{s}$ altogether, and since the velar fricatives $/ \mathrm{x} /$ and $/ \mathrm{\gamma} /$ always agree in voicing with the following consonant in clusters (all other possibilities $* k n-,{ }^{*} x n-,{ }^{*} g n-$, are not acceptable clusters in Japhug). Note that irregular nouns in Table 4 are attested for only verbal roots with a simple initial consonant, without any cluster (prenasalized voiced obstruents count as one phoneme in Japhug). This is by no means a coincidence, but rather an effect of the fact that with clusters, the $/ \mathrm{k}-/$ prefix would have been dropped without a trace.

Alongside the nouns in table 4, all four verbs allow the phonologically and semantically regular corresponding nominalized forms (ku-pas 'the black one', ku-so 'the empty one' etc), which were regularly created after the irregular nominalizations became opaque.

The irregular loss of vowels in the examples in table 4 is by no means limited to the nominalization prefix $k u-$, as it is also observed with the animal class prefixes $k u$ - which becomes $x-/ \gamma$-in some examples but not in others. Comparison with Situ Rgyalrong, which never undergoes vowel loss in prefixes, allows one to detect these examples.

Table 5: Sporadic vowel attrition in the animal class prefixes in Japhug

\begin{tabular}{|c|c|c|}
\hline Japhug & meaning & Situ \\
\hline 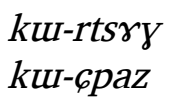 & $\begin{array}{l}\text { leopard } \\
\text { marmot }\end{array}$ & $\begin{array}{l}k \partial-\epsilon t \epsilon i ́ k \\
k^{h} e-\int p \hat{s} s\end{array}$ \\
\hline $\begin{array}{l}\gamma^{-Z u U} \\
\gamma^{-} n i\end{array}$ & $\begin{array}{l}\text { monkey } \\
\text { flying squirrel }\end{array}$ & $\begin{array}{l}\text { kə-tsú } \\
\text { ka-ní }\end{array}$ \\
\hline
\end{tabular}

The examples in Table 5 suggest that vowel attrition only takes place in words whose second syllable has a simple onset (does not begin in an

\footnotetext{
${ }^{8} \mathrm{~A}$ few minor exceptions are discussed in Jacques (2004: 45, 261), but are of no incidence to the present discussion.
} 
initial cluster), a feature shared with the examples of Table $4 .{ }^{9}$

Vowel attrition of prefixes occurs either with non-productive prefixes such as the animal class prefix or with productive prefixes (such as the $\mathrm{S}$ / A nominalization prefix $k u-$ ) that become reanalysed as a part of the stem due to the semantic evolution of the deverbal noun in question. Another such example is studied in section 2.2.2.

\subsubsection{Action nominals}

Beside the argument and adjunct nominalization prefixes studied in the previous subsection, we also find action or result nominals in tur-

The literature on Rgyalrong languages designates these forms as 'action nouns' (Jacques 2004: 455) or 'lexicalized action nominals' (Sun and Lin 2007). ${ }^{10}$

Action nominals can be used to refer to the action or process designated by the verb. They can occur in constructions with a light verb such as (7), or as the complement of the verb za 'to begin' (8); both intransitive and transitive verbs can participate in such constructions.

(7) tur-rfas pur- $\beta z u-t-a$

NMLZ:ACTION-dance PFV-do-PST-1SG

'I danced.'

(8) u-di tu-mnrm ta-za tce $c^{h a}$

3sG.POSS-smell NMLZ:ACTION-smell PFV:3 $\rightarrow 3$-begin LNK alcohol

to-rrru tu-ti-nu gu

EVD-get.up IPFV-say-PL NPST:be

'When it starts to smell, people say 'the alcohol has fermented'.' (Alcohol, 77)

Action nominals cannot take any TAM markers but can receive possessive prefixes. However, the possessor does not necessarily correspond to any of the arguments of the original verb. For instance, in the case of the noun tur-rfas 'a dance' derived from the intransitive rfas 'to dance', possessive prefixes as in $u$-tu-rfab 'his dance' are generally interpreted as the beneficiary of the action, not the dancer ('a dance performed in his honour').

\footnotetext{
${ }^{9}$ In any case, even if counterexamples to this generalization are found, this would not be surprising, as vowel attrition in presyllables and monosyllabicization tend to be a sporadic process in its first stages (see Michaud 2012).

${ }^{10}$ There are two distinct scholarly traditions on this particular topic, Comrie (1976) and Koptjevskaja-Tamm (1993: 5) on the one hand who use the terms 'action nominal' and 'action nominal constructions', and Grimshaw 1990 on the other hand, whose work focusses on the distinction between process and result nominals which is not taken into account in Koptjevskaja-Tamm (1993). We retain here the term 'action nominal'; this construction would be labelled as 'result nominal' in Grimshaw's framework.
} 
With stative verbs, tu- nominals express the abstract property of the verb (like the derivation of nouns from adjectives by the suffix -ness in English) and are better labelled as 'property nominals'. tu- nominals commonly occur in a degree construction, followed by another stative verb in-

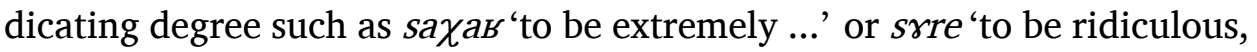
to be terribly ...'.

(9) Bушz пш li u-di uu-tu-srjlos badger TOP too 3SG.POSS-smell 3SG.POSS-NMLZ:PROPERTY-awful srre $\quad$ zo NPST:terrible EMPH

'The badger's smell is awful.' ('the badger's smell's awfulness is terrible')

Unlike the argument nominals discussed in the previous subsection, turaction nominal derivation is not fully productive, and the semantics of the action nominals is not always predictable. In some cases, it refers to the result of the action rather than the action itself (thus tur-tas 'woven cloth' from $t a s^{\prime}$ 'to weave') or even the object of the action ( $t u-t s{ }^{h}$ ' 'rice porridge' from $t s^{h} i$ 'to drink') and the semantics of the noun is not always predictable and tends to be more specific than that of the verb. It is however crosslinguistically quite common for action nominals to present this kind of irregular semantics for some nouns (Koptjevskaja-Tamm 1993: 20-21).

Table 6 illustrates the most representative examples of such irregular nouns. Apart from numerous examples with irregular semantics, we also find two examples with irregular phonology.

Table 6: Examples of irregular action nominals and their base verbs

\begin{tabular}{lllll}
\hline noun & meaning & base verb & meaning & irregularity \\
\hline tusqa & wheat porridge & $s q a$ & cook & semantics \\
tupu & moxibustion & $p u$ & cook in ashes & id. \\
tupyas & land reclamation & pуas & turn over & id. \\
\hline tutsye & commerce & $n t s y e$ & sell & phonology \\
-nga & debt & na & owe & id. \\
\hline
\end{tabular}

In the following, we provide a detailed account of one action nominal with irregular semantics (tируав 'land reclamation') as well as of the the two action nominals with irregular phonology. These three examples will be relevant to our hypothesis on the origin of the antipassive in section 4 .

Irregular semantics The transitive руав 'to turn around, turn over' has numerous meanings. It can be applied to sheet-like objects, and with clothes it can even mean 'to wear inside out'. It has other specialized meanings like 
'to cross a mountain', 'open the cover/lid' or 'to plough a field', with different directional prefixes.

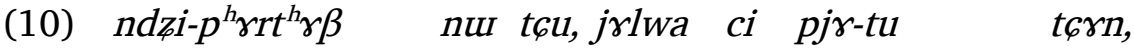
3DU.POSS-between TOP LOC curtain one EVD.IPFV-exist COORD

nu qale ci ku to-pyab ri

DEM wind one ERG EVD-turn.over but

'Between them, there was a curtain, and a wind turned it over.' (The frog, 98)

(11) uा-fkaß ta-руав

3SG.POSS-cover PFV:3 $\rightarrow 3$ :UP-turn.over

'He opened the cover.' (Lobzang, 49)

The meaning 'to plough' is always associated with directional prefixes indicating the 'upstream' direction (the same as all verbs meaning 'to dig' in the language):

(12) tuji la-руав

field PFV:3 $\rightarrow 3$ :UPSTREAM-turn.over

'He ploughed the field.'

On the other hand, the nominalized form of the verb only has one meaning: the action of reclaiming land by ploughing for the first time (in Chinese 开荒 kaihuang), as illustrated by the following example from the Flood myth:

\section{tu-руав lo-ţrt-ndzi}

NMLZ:ACTION-turn.over EVD:UPSTREAM-take.out-DU

'They ${ }^{d u}$ reclaimed land.' (The flood, 85)

Irregular phonology As the argument nominals discussed in 2.2.1, there are also a few action nominals with irregular phonology.

First, the transitive verb ntsye 'to sell' has an action noun tutsye 'commerce' which presents a stem / tsye/ distinct from that of the base verb in lacking a $n-$. An explanation for the additional $n$ - in $n t s y e$ 'to sell' will be proposed in section 4.4 .

Second, the possessed noun -nna 'debt' appears to be related to the verb na 'to owe' but it lacks a derivational tu- prefix and has a additional $n-$ element. ${ }^{11}$ In the following, we will show that this $n$-is a trace of the derivational $t u-$ prefix.

\footnotetext{
${ }^{11}$ Since $-n \eta a$ is a inalienably possessed noun, its form without definite possessive prefix is tur-nja, but the tu-here is the indefinite possessor prefix, and alternates with the series of possessive prefix in Table 2.
} 
We saw in section 2.2.1 (Table 4) that irregular argument nominals were formed by deleting the vowel of the derivational prefix and applying automatic phonological changes to the prefixed stop ( $k u$ - becomes $\gamma^{-}$or $x$ - in these nouns). We mentioned that comparative evidence with Situ Rgyalrong indicate that velar and labial stops underwent fricativization in Japhug when occurring as first member of clusters having an obstruent as second member. In the case of coronal stops however, clusters with / $\mathrm{t} /$ or / $\mathrm{d}$ / followed by a consonant other than a non-nasal sonorant exist in Japhug in internal position (though mainly in loanwords from Tibetan across morpheme boundaries).

Let us now observe the synchronic distribution of clusters which have a nasal as second member in Japhug (data from Jacques 2004).

Table 7: Clusters with a nasal as a second member in Japhug

\begin{tabular}{llll}
\hline & labial & dental & velar \\
\hline $\begin{array}{l}\text { labial } \\
\text { dental }\end{array}$ & $n m-$ & $m n-$ & $m \eta-$ \\
velar & $y m-$ & $y n-$ & \\
\hline
\end{tabular}

We see that there are no clusters with a nasal velar as the first element (*nm-, * $\eta n-)$ but that on the other hand there are no clusters with a dental or a labial non-nasal (* $\left.\beta n-,{ }^{*} t n-\right)$. Moreover, $n$ - as the first element of a cluster has a very restricted distribution. It occurs only (i) before a coronal stop or affricate (clusters such as $/ n t^{h}-/, / n t s-/$ etc, where it is the realization of the homorganic nasal archiphoneme $/ \mathrm{N} /$ ), (ii) before voiced prenasalized stops $(/ n m b /$ and $/ n \eta g /$, transcribed as $n b-$ and $n g-$ in this work) (iii) before nasal consonants (the examples in Table 7). $n$-is conspicuously absent as the first element of a cluster before labial and velar stops (outside of the voiced prenasalized one). Thus, one does not find clusters such as *np- or *nk ${ }^{h}$ in Japhug.

If $n$ - as first element of a cluster in cases (ii) and (iii) originated from *n- in pre-Japhug, there would be no reason why only $n m b-$ and $n m-$ are possible while $* n p$ - and $* n p^{h}$ - are not. A solution to this paradox is to assume that $n$-in cases (ii) and (iii) originate from */t/, which underwent retrograde nasality assimilation, as indicated in table 8. 
Table 8: Retrograde nasality assimilation in Japhug clusters

\begin{tabular}{ll}
\hline pre-Japhug & Japhug \\
\hline$* t m-$ & $n m-$ \\
$* t \eta-$ & $n \eta-$ \\
${ }^{*} t m b-$ & $n b_{-}$ \\
$* t \eta g-$ & $n g-$ \\
\hline
\end{tabular}

The best evidence for this sound law comes from loanwords from Tibetan, where internal $t+$ nasal clusters automatically undergo these changes (for instance Tibetan $m t c^{h}$ od.me 'traditional lamp' and rgod.ma 'mare' were borrowed as $m t^{h}{ }^{h}$ mmi and $\left.r g o n m a\right) .{ }^{12}$

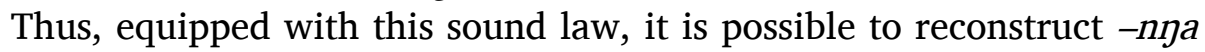
'debt' as *tma in pre-Japhug, a form coming from the expected regular form *tuma by loss of the vowel. This is the only known case in Japhug when a action nominal prefix $t u$ - undergoes irregular vowel loss.

This particular example will be relevant to our discussion in section 4 on the origin of the antipassive in Japhug.

\subsubsection{Bare infinitive and derived inalienably possessed nouns}

Besides $t u$ - prefixed nominals, we also find another type of action nominal: bare infinitives. These non-finite forms are formed by combining the bare base stem with a possessive prefix coreferent with the patient, as $u$-mto in (14). Only transitive verbs can form bare infinitives (intransitive verbs use $k r$ - prefixed forms in the same contexts).

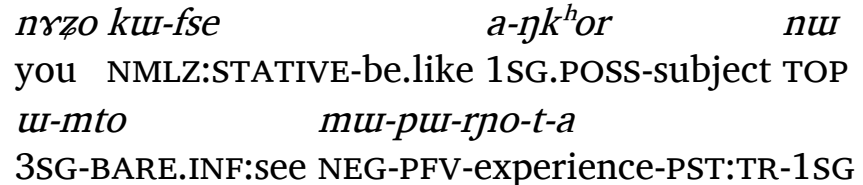

'I never saw anyone like you among my subjects.' (Smanmi metog koshana1.157)

We also find bare infinitives instead of action nominals with the verb za 'to start' when the patient is an overt noun phrase, as in example 15.

(15) trscoz uu-rrt pa-za

letter 3SG.POSS-BARE.INF:write PFV:3 $\rightarrow 3$-start

'He started writing a letter.' (elicited)

The bare infinitive can also be used as an action nominal in combination with the noun $t s^{h} u r y a$ 'form, appearance' as in example (16).

\footnotetext{
${ }^{12}$ The Tibetan translitteration used here follows Jacques (2012a).
} 
ndzi-mi uu-ts ${ }^{h} O B \quad$ ut-ts ${ }^{h}$ urya nura

3DU.POSS-foot 3SG-BARE.INF:attach.to 3SG.POSS-form TOP:PL

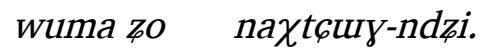

very EMPH NPST:similar-DU

'The way their feet (of fleas and crickets) touch the ground is very similar.' (the cricket 17)

In addition to bare infinitives, there is a rarer formation of bare action nominalizations by prefixation of possessive prefixes to the bare stem of verbs; the indefinite possessor is either $t u$ - or $t \gamma$ - (Table 9).

Table 9: Bare nominalizations (inalienably possessed nouns)

\begin{tabular}{lllll}
\hline base verb & meaning & noun stem & $\begin{array}{l}\text { indefinite } \\
\text { possessor }\end{array}$ & meaning \\
\hline$f k a \beta$ & cover & $-f k a \beta$ & $t \gamma$-fkaß & lid \\
$6 p^{h} \gamma t$ & patch & $-6 p^{h} \gamma t$ & $t \gamma$ - $6 p^{h} \gamma t$ & patch (n.) \\
suuso & think & - suso & tul-sulso & thought \\
\hline
\end{tabular}

Given the absence of morphemes other than the possessive prefixes, it is legitimate to wonder whether the direction of derivation in the examples in Table 9 is indeed from verb to noun as posited here. The proof that this is indeed the correct direction of derivation is the fact that the verb $f k a \beta$ 'to cover' is borrowed from Tibetan $b k a b$, the past tense form of the verb " $g e b s$ 'to cover'. The noun $-f k a \beta$ 'cover' is clearly secondary and was created within Japhug, as there is no such corresponding noun in Tibetan.

\subsection{Transitivity in Japhug}

Since the focus of this paper is on valency-decreasing derivation, it is necessary to provide some information on transitivity marking in Japhug. Japhug, like all Rgyalrong languages, has a very clear distinction between transitive and intransitive verbs, which is reflected in both case marking and verbal morphology. Morphological transitivity is unambiguous and marked in different but congruent ways, some of which have been mentioned above.

First, Japhug is a strongly head-marking language, with person and number of both arguments marked on the verb (Jacques 2010a). Only transitive verbs can receive the inverse prefix $w y u-$, the portmanteau prefixes $k u-(2 \rightarrow 1)$, ta- $(1 \rightarrow 2)$, the perfective direct $3 \rightarrow 3$ ' a- prefix or the $1 / 2 \mathrm{SG} \rightarrow 3-t$ suffix (the latter only occurs in open-syllable stem verbs).

Second, Japhug has ergative flagging: $S$ and $P$ are unmarked (examples 17 and 18), while the A of a transitive verb receives the clitic ku (example 18). This clitic is obligatory with nouns and third person pronouns, but 
optional for first and second person pronouns. The $k u$ clitic can also be used to mark instruments.

$$
\begin{aligned}
& \text { tr-tcui nu jo-ce } \\
& \text { INDEF.POSS-boy TOP EVD-go }
\end{aligned}
$$

$$
\begin{aligned}
& \text { tr-tcui nu ku } \chi s \gamma r \text { qacpa nu } c^{h} \gamma \text {-mqlas } \\
& \text { INDEF.POSS-boy TOP ERG gold frog TOP EVD-swallow }
\end{aligned}
$$

The boy swallowed the golden frog.' (Nyima Wodzer.1, 131)

Third, some transitive verbs present a special stem in direct $123 \mathrm{SG} \rightarrow 3$ forms. The regular pattern is that verbs whose stem is in $-o,-u,-a$ and $-u$ change to $-r m,-e,-e$ and $-i$ respectively. This stem alternation does not occur with intransitive verbs.

Fourth, argument nominalisation of transitive and intransitive verbs present tripartite alignment, as the S nominalization is marked by $k u-$ , while A nominalization is marked by a possessive prefix followed kuand P-nominalization by $k r$ - (section 2.2.2). Argument nominalization can therefore always be used to distinguish transitive from intransitive verbs.

There are a few labile verbs is Japhug, and all present agent-preserving ambitransitivity (Jacques 2012b: 217-9). When used intransitively, labile verbs are interpreted as having an undefined patient, as in example (19).

$$
\begin{aligned}
& \text { t6 }{ }^{h} \text { eme ci pu-tas jü-pu } \\
& \text { girl INDEF PST.IPF-weave CONST-be } \\
& \text { 'A girl was weaving.' (The demon, 28) }
\end{aligned}
$$

Non-overt patients of non-labile transitive verbs on the other are always interpreted as a referent previously mentioned in the text. Thus, in a sentence such as 20, the verb tu-ndze (IPF-eat[III]) can only mean 'eat it', never 'eat something'. ${ }^{13}$
tuji ut-ngu
tce, qapri ku tu-ndze

field 3sG.POSS-inside LNK snake ERG IPF-eat[III]

ngrrl tce, kha tce lulu ku tu-ndze

NPST:be.usually.the.case LNK house LNK cat ERG IPF-eat[III]

ju

NPST:be

'In the field, snakes eat them (mice) and in the house, cats eat them.' (Mice, 163-4)

\footnotetext{
${ }^{13}$ In this particular example, the non-overt patient is mice as a species, which were referred to previously in the text; in Japhug generic referents can be either singular or plural.
} 
There are three ways to have an unspecified patient with a non-labile transitive verb. First, the generic human marker $k u-$ can be prefixed to the verb. ${ }^{14}$ Second, an indefinite pronoun such as $t^{h} u c i$ 'something' can be used. Third, the verb can be intransitivized by means of an antipassive prefix.

Example 21 illustrates a switch of use between the antipassive $s \gamma$ - and the generic $k u-$ across two sentences.
nut aвrndundrt uI-grrl
kut-me
DEM everywhere 3SG.POSS-order NMLZ:S/A-not.exist
kul-sr-mtsury jul-pu. nu ku
NMLZ:S/A-ANTIPASS:HUMAN-bite CONST-be DEM ERG
a-kr-kut-mtsury tce tce nut uu-tury
IRR-PFV-GENR:S/P-bite LNK LNK DEM 3SG.POSS-poison

yrzu. the tuzo jui-ku-cte jui-pu.

SENSORY:exist LNK GENERIC IPFV-GENR:S/P-infect CONST-be

'(Rabid dogs) bite people without discrimination, and if one is bitten by them, there is poison (in their bites) and one gets infected.' (Rabies, 8)

This sentence shows that using the generic form allows anaphoric reference (the P of the verbs a-kr-ku-mtsur 'if one is bitten' and nur-ku-cte 'one gets infected' must be the same generic referent), while the antipassive implies that the deleted $\mathrm{P}$ is not identifiable (on this topic see Cooreman 1994: 52) and no anaphoric reference is possible.

\section{Antipassive in Japhug}

Two productive antipassive prefixes are found in Japhug: $r \boldsymbol{r}$ - and $s \boldsymbol{\gamma}-{ }^{15}$ The former is used to delete a non-human patient ( $6 a r$ 'to search' $\rightarrow r \gamma-6 a r$ 'to search for things') while the second is used to delete a human patient ( 6 ar 'to search' $\rightarrow s \gamma$ - $6 a r$ 'to search for people'). ${ }^{16}$ The patient cannot be reintroduced with oblique case in Japhug antipassive constructions, except for some ditransitive verbs (3.2) . Labile verbs cannot form antipassives.

\footnotetext{
${ }^{14}$ The generic marker for S and P in Japhug is kut-, a prefix unrelated at least synchronically to the homophonous nominalization prefix ku- (Jacques 2012b: 204-89). Generic marking in Japhug will not be discussed in this paper. Unlike human antipassive, generic patients in $k u-$ can be topical, and this form is typically used in gnomic statements and procedural texts.

${ }^{15}$ There is a third antipassive prefix $6 u m$ - only attested with the verb $t^{h} u$ 'to ask' $\rightarrow$ cumt ${ }^{\text {h } u}$ 'to ask a lot of questions'.

${ }^{16}$ A similar situation is found in the closely related language Tshobdun, (Sun 2006: 8), and a typological parallel is observed in Nahuatl which also has a human antipassive $t \bar{e}-$ and a non-human antipassive tla- (Creissels 2006: 91).
} 
As illustrated in table 10, the formation of the non-human $r r$ - antipassive is perfectly regular (it has an allomorph ra- before a uvular fricative in closed syllables), except for the verbs ga 'to owe" and ntsye 'to sell', the first of which is discussed in detail in section 4.1.1.

Table 10: Examples of the antipassive prefix $r \gamma$

\begin{tabular}{|c|c|c|c|}
\hline & basic transitive verb & \multicolumn{2}{|c|}{ derived intransitive verb } \\
\hline гов & to carve & гу-гов & to carve things \\
\hline $\operatorname{tgr} \beta$ & to burn & $r \gamma-\operatorname{tg} \gamma \beta$ & to burn land \\
\hline $6 p^{h} \gamma t$ & to patch & $r \gamma-\epsilon p^{h} \gamma t$ & to patch things \\
\hline руаь & to turn over & $r \gamma-р у а в$ & to reclaim land \\
\hline$t$ suu $\beta$ & to sew & $r \gamma-t s u \beta \beta$ & to sew things \\
\hline car & to search & $r \gamma-6 a r$ & to search for things \\
\hline па & to owe (a specific quantity) & rr-nпа & to owe money \\
\hline ntsye & to sell & $r \gamma$-tsye & to sell things \\
\hline$\chi \chi^{t u}$ & to buy & 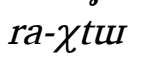 & to buy things \\
\hline
\end{tabular}

The non-human antipassive $r \gamma$ - detransitivizes transitive verbs, and the $S$ of the derived verb corresponds to the A of the base verb: this is an agentpreserving derivation, unlike the passive and anticausative. The verb takes an intransitive conjugation and the $S$ appears without ergative marking:

$$
\text { tr-rzaß nu } p j \gamma-r \gamma-\epsilon p^{h} \gamma t
$$

INDEF.POSS-wife TOP EVD-ANTIPASS:NON.HUMAN-mend

'The wife mended (clothes).' (The raven 19)

The human antipassive $s \gamma$ - prefix presents the allomorph $s a-$ before a uvular fricative in closed syllables and the optional variant $s \gamma z-$ in a few verbs whose stem begins in $\mathrm{r}^{\mathrm{r}-}$.

Table 11: Examples of the antipassive prefix $s \gamma-$

\begin{tabular}{|c|c|c|c|}
\hline \multicolumn{2}{|c|}{ basic transitive verb } & \multicolumn{2}{|c|}{ derived intransitive verb } \\
\hline уrmü & to praise & $s \gamma-\gamma \gamma m u, s \gamma z-\gamma \gamma m u$ & to praise people \\
\hline car & to search & $s \gamma-6 a r$ & to search for people \\
\hline$t \epsilon^{h} u$ & to gore & $s \gamma-t \epsilon^{h} u U$ & to gore people \\
\hline mtsury & to bite & sq-mtsury & to bite people \\
\hline nrmtsion & to peck & sr-nrmtsion & to peck at people \\
\hline Bndu & to hit & sa-sndu & to hit people \\
\hline
\end{tabular}

In the closely related Tshobdun language, ? reports two distinct patientsuppressing $s \boldsymbol{b}$-prefixes, ${ }^{17}$ the human antipassive $s \boldsymbol{E}$ - (deriving action verbs,

\footnotetext{
${ }^{17} s E$ - in Tshobdun is the form regularly corresponding to Japhug $s \gamma-$.
} 
as $n t \int^{h} e$ 'to kill' $\rightarrow s e ́-n t \int^{h} e$ 'to do killing (of people)') and a prefix $s e-$ deriving stative verbs meaning 'to have a propensity for $\mathrm{V}$-ing' ( $t \int^{h} u$ ? 'to gore' $\rightarrow s e-t \int^{h} u$ ? 'to have a propensity for goring (people)').

In Japhug, the situation is very similar to that of Tshobdun, but it is unclear whether two distinct prefixes must be posited. Human antipassive verbs can be either action verbs or propensity stative verbs depending on the context.

For instance, the human antipassive $s \gamma$-sat of the transitive verb sat 'to kill' can be both used as a propensity stative verb $s \gamma$-sat 'have a killing power' (example 23) or as an action verb 'to kill people' (examples 24 and 25). It should be noted that the implied patient of propensity stative verbs is generally human, but in some cases can be applied to animals as well. For instance $s \gamma$-sat 'have a killing power' can designate the killing of both animals or people.

(23) nunu wuma ъо nu-sr-sat this very EMPH CONST-ANTIPASS:HUMAN-kill

'Its killing power is considerable (of a gun).' (Guns, 117)

(24) $k \gamma$-s $\gamma$-sat pjr-rno

INF-ANTIPASS:HUMAN-kill EVD-experience

'He has killed [a man] before.' (In Chinese: 他杀过人)

$$
\begin{aligned}
& \text { kut-s } r \text {-sat } \\
& \text { NMLZ:S/A-ANTIPASS:HUMAN-kill EVD-go }
\end{aligned}
$$

'He went to kill [people].'

In general, human antipassive verbs appear to allow both meanings. For instance, the antipassive $s \gamma$-mtsury derived from mtsur 'to bite' means both 'to have a propensity for biting people' and 'to bite people' depending on the context. Depending on the meaning of the base verb, some human antipassive verbs will more commonly tend to be action verbs; for instance, $s \gamma$ - $6 a r$, the antipassive of $c a r$ 'to search', is usually an action verb 'to search for people' and cannot really be interpreted as meaning 'to have a propensity for searching for people' but this is probably more for pragmatic reasons than morphosyntactic ones.

Thus, we will not distinguish in this paper the action human antipassive from the stative antipassive, as this distinction in Japhug reflects specific uses of a single derivation rather than distinct derivations. The tendency of the antipassive construction to express repeated or habitual action rather than a punctual event is well attested cross-linguistically (cf Cooreman 1994: 91-2). 


\subsection{Compatibility with other derivational prefixes}

Jacques 2012c describes the Japhug verb in terms of the template in Table 12 (Jacques 2012c). This table represents finite verb forms. In nominalizations, the prefixal slots 1, 5, 6 and all suffixal slots, which mark TAM and person, cannot be filled. Nominalization prefixes described in 2.2 always occur between slots 4 and 5 . 


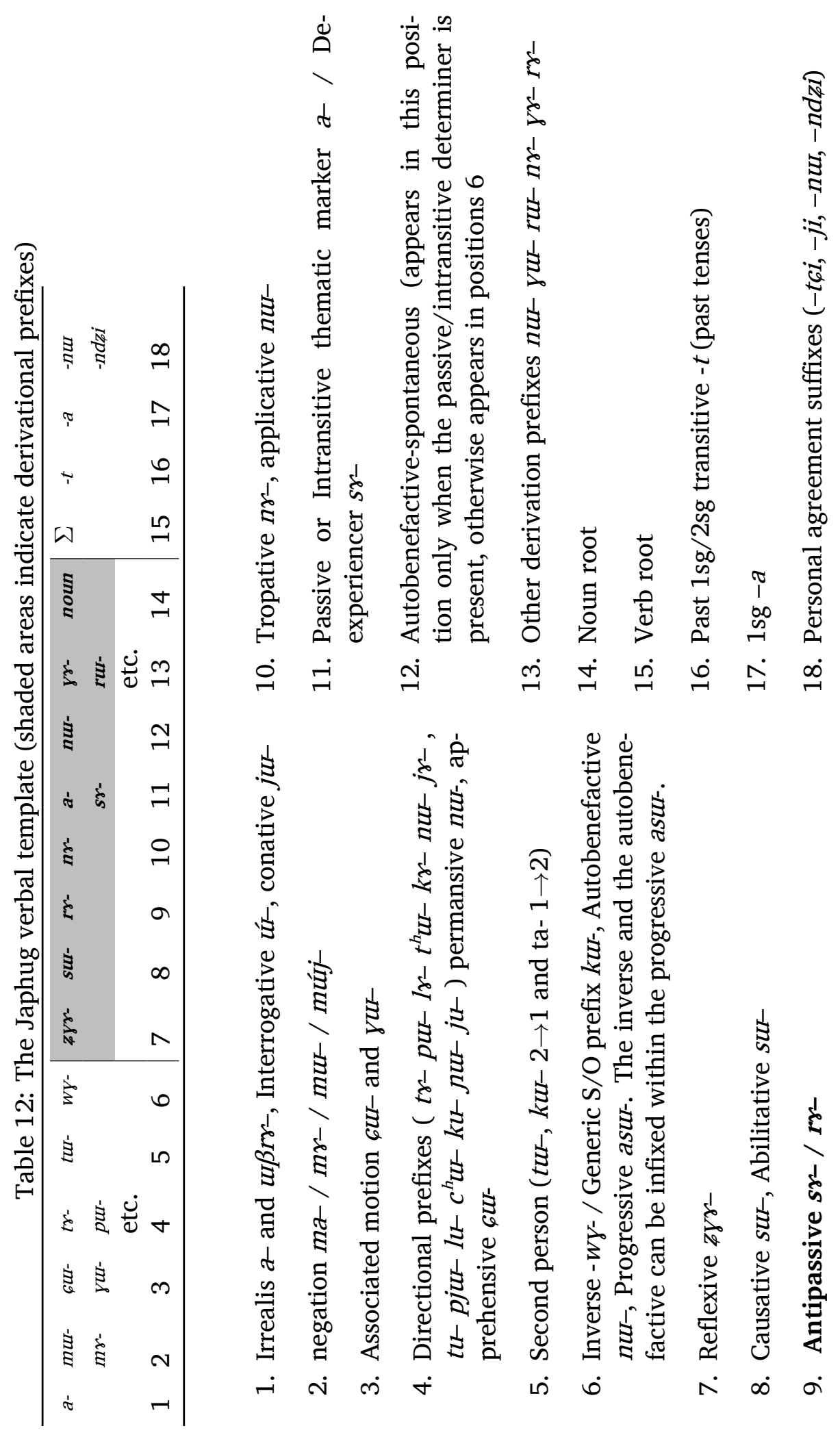


As indicated in Table 12, antipassive prefixes occur after the causative prefix, but before the tropative and denominal prefixes.

Example 26 illustrates the combination of an antipassive after the $z-$ allomorph of the causative prefix.

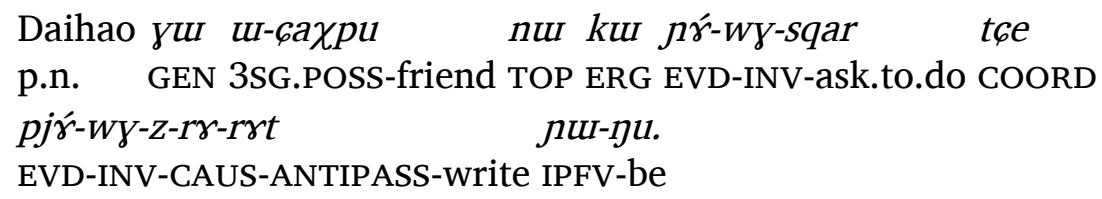

'A friend of Daihao's asked him to draw paintings.' (The painter and the shepherd boy, 10)

The verb $z-r \gamma-r \gamma t$ 'to cause to make drawings/writings' derives from the antipassive $r \gamma-r \gamma t$ 'to make drawings/writings' of the transitive verb $r \gamma t$ 'to paint, to write'.

The reversed prefix order, namely ANTIPASS-CAUS-, appears to be attested in one example: $r \gamma$-j-ts ${ }^{h}$ 'to give (to) people to drink'. ${ }^{18}$ However, this example is not a real counterexample to the verbal template in Table 12.

The antipassive $r \gamma-j$-ts ${ }^{h}$ derives from the irregular causative $j$-ts ${ }^{h} i$ 'to give to drink' of the verb $t s^{h} i$ 'to drink'. However, this is a lexicalised causative, and there is no compelling evidence for considering the element $j$ - as a causative prefix synchronically; the regular causative $s u-t s{ }^{h}$ 'to cause to drink' with fully predictable semantics also exists, ${ }^{19}$ and there is no other example of the allomorph $j$ - of the causative prefix.

The antipassive cannot occur to the left of a regular causative prefix; forms such as ${ }^{*} s \gamma$-su-ts ${ }^{h} i$ or ${ }^{*} r \gamma$-su- $t s^{h} i$ (intended meaning 'to cause someone to drink' or 'to cause to drink something') are categorically rejected by native speakers.

There are three examples of antipassives combined with the tropative $n \boldsymbol{r}$-, a prefix that derives a transitive verb meaning 'to find ..., to consider ...' from a stative verb. For instance, $s \gamma-n \gamma-m p \varphi \gamma r$ 'to consider people beautiful' derives from the tropative $n \gamma$-mp $6 \gamma r$ 'to find beautiful' of the verb mpcrr 'to be beautiful'.

Finally, the antipassive prefixes commonly appear before denominal prefixes. For instance, the verb $s \gamma-n u-\beta l u$ 'to trick people' derives from the transitive denominal verb nul- $\beta$ lu 'to trick' which itself originates from the inalienably possessed noun $u-\beta l u$ 'trick', a loanword from Tibetan blo 'mind, method, trick'.

\footnotetext{
${ }^{18}$ See section 3.2 for the reason why $r \gamma$ - is present here instead of $s \gamma$-.

${ }^{19}$ The semantic difference between the irregular causative $j t s{ }^{h} i$ and the regular one $s u-t s{ }^{h} i$ is very clear. The former specifically means 'to give something to drink to ease thirst', while the second has the full range of meanings of causatives, including 'to force to drink', 'to cause to drink inadvertently' and 'to drink with (an instrument)'.
} 
Combinations of antipassive prefixes with other prefixes are not attested in our present corpus, but this is mainly due to issues of performance (to think of an appropriate context where a word combining for instance antipassive, tropative and de-experiencer could be used) than an effect of grammatical constraints on prefix combination.

\subsection{Antipassive of secundative ditransitive verbs}

Ditransitive verbs in Japhug never mark more than two arguments on the verb, and most present indirective alignment: the theme (the given entity) is coded in the same way as the patient of a monotransitive verb. ${ }^{20}$ These verbs are attested with both human and non-human antipassive; for instance $t^{h} u$ 'ask' yields both $r \gamma-t^{h} u$ 'ask something' and $s \gamma-t^{h} u$ 'ask someone in marriage'. The antipassive cannot be used to delete the recipient for indirective verbs.

However, there are also two verbs with secundative alignment, whose recipient is coded as the patient of a monostransitive verb ( $m b i$ 'to give' and $j t s{ }^{h} i$ 'to give to drink'), as shown in example 27.

$$
\begin{aligned}
& n \gamma-p i \quad n i \quad k u \text {... qrjyi nura } \\
& \text { 2sG.POSS-elder.sister DU ERG ... bread TOP:PL } \\
& \text { ku-mum zrni tu-nu-ndza-ndzi, u-rku } \\
& \text { NMLZ:STATIVE-tasty they.DU IPF-AUTO-eat-DU 3sG.POSS-side }
\end{aligned}
$$

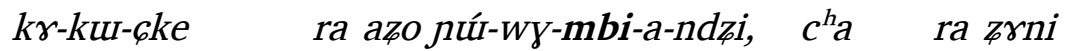

$$
\begin{aligned}
& \text { PFV-NMLZ:S-burn PL I PFV-INV-give-1SG-DU alcohol PL they.DU } \\
& \text { ku-nu-ts }{ }^{h} \text {-ndzi, } \quad \text { ąo ü-ьfo } \\
& \text { IPF-AUTO-drink-DU I 3SG.POSS-diluted.alcohol } \\
& \text { jút-WY-jtshi-a-ndzi pul-cti } \\
& \text { PFV-INV-give.to.drink-1SG-DU PST.IPF-be.ASSERT }
\end{aligned}
$$

'Your two sisters (...) ate the tasty food and gave me the burned part of the bread, drank the alcohol and gave me diluted alcohol to drink.' (The three sisters, 68).

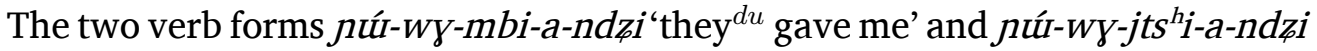
'they ${ }^{d u}$ gave me to drink' are $3 \mathrm{DU} \rightarrow 1 \mathrm{SG}$, and the theme is not marked on either verb.

Since recipients are prototypically human, one would expect that the antipassive of these secundative ditransitive verbs would be formed using the $s \gamma$-human antipassive. However, when they undergo antipassivization, these verbs take the prefix $r \gamma$-instead of $s \gamma$-. The theme can be present in the sentence, though the verb is morphologically intransitive, and the agent is not marked in the ergative. Thus, in 28 , had the verb been transitive a

\footnotetext{
${ }^{20}$ We follow here Malchukov et al. (2010)'s terminology.
} 
transitive past suffix $-t$ would have been expected between the verb stem and the personal suffix. ${ }^{21}$

(28) stos nut-ry-mbi-a bean PFV-ANTIPASS-give-1SG

I gave beans (to someone).

In 28, the recipient is unspecified, but unlike antipassive verbs derived from simple transitive verbs, it can be reintroduced with an oblique case (dative marking):

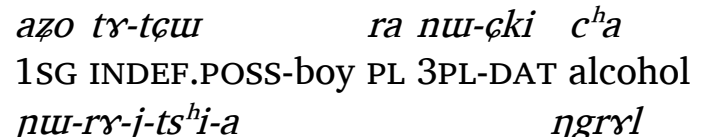

IPFV-ANTIPASS-CAUS-drink-1SG N.PST:be.usually.the.case

I usually give drinks to the guys.

Constructions like 29 with antipassive and an overt recipient are uncommon but can be elicited.

\subsection{Denominal prefixes}

Japhug has a rich array of denominal prefixes, two of which are formally identical to the antipassive $r \gamma$ - and $s \gamma$-. This homophony raises the question whether these prefixes are diachronically related, which will be discussed in 4.

In this section, we offer general information on denominal derivations and describe in more detail the $r \boldsymbol{r}$ - and $s u$ - derivations specifically.

\subsubsection{Denominal derivation}

There is no evidence of denominal zero derivation in Japhug; derivation from noun to verb requires the addition of one of the seven denominal prefixes (Jacques 2012c: 1217, cf Table 13).

\footnotetext{
${ }^{21}$ Its transitive equivalent is nu-mbi-t-a PFV-give-PST:TR-1SG 'I gave it to him', a form where the recipient is always definite.
} 
Table 13: List of denominal prefixes in Japhug

\begin{tabular}{|c|c|}
\hline Form & Property \\
\hline$n u-, n \gamma-$ & intransitive and transitive \\
\hline$r u-, r \gamma-$ & intransitive and transitive \\
\hline$\gamma u-, \gamma^{\gamma-}$ & intransitive and transitive \\
\hline sut-, sł-, sur- & transitive verb with instrument, intransitive verb of position \\
\hline$m \gamma-$ & transitive verb with body part, intransitive verb of position \\
\hline$s \gamma-$ & intransitive verb (property) \\
\hline aуu- & intransitive verb (property) \\
\hline
\end{tabular}

When inalienably possessed nouns and quantifier nouns undergo denominal derivation into verbs, the possessive prefixes and the numeral prefixes are invariably suppressed, as shown by the examples in Table 14.

Table 14: Examples of denominal verbs from inalienably possessed and quantifier nouns

\begin{tabular}{llllll}
\hline Category & Transitivity & Derived verb & Meaning & Base noun & Meaning \\
\hline inalienable & intr. & $r \gamma-\eta g u m$ & to lay an egg & - ggum & egg \\
& intr. & $r u-c m i$ & to speak & $-6 m i$ & word \\
& tr. & $n u-\gamma m a z$ & to wound & $-\gamma m a z$ & wound \\
& tr. & $n u-j r o b$ & to follow a trail & $-j r o b$ & footprints \\
& tr. & $s \gamma-r m i$ & to give a name & $-r m i$ & name \\
\hline quantifier & tr. & $r \gamma-t \gamma a$ & to mesure by span & $-t \gamma a$ & handspan \\
\hline
\end{tabular}

Some of these prefixes present two allomorphs, one with $u$ vocalism and the other with $r$ vocalism. When the base noun is inalienably possessed, the vocalism of the denominal prefix generally follows that of the indefinite possessor: when the base noun has tut-, the derived verb will have a denominal prefix in rut-, nu-, su- or $y u-$, and when the base noun has an inalienably possessed prefix in $t \gamma$-, the denominal verb will have the $\gamma$ series of prefixes $r \gamma-, n \gamma-, s \gamma$ - or $\gamma^{\gamma}$-. This rule however has a few exceptions.

For quantifier nouns and all other nouns, both $u$ and $r$ denominal prefixes are attested. 
Table 15: Vocalism of the denominal prefixes

\begin{tabular}{|c|c|c|c|c|c|}
\hline $\begin{array}{l}\text { Indefinite } \\
\text { possessor }\end{array}$ & noun stem & meaning & $\begin{array}{l}\text { denominal } \\
\text { prefix }\end{array}$ & $\begin{array}{l}\text { derived } \\
\text { verb }\end{array}$ & meaning \\
\hline$t r-$ & $-1 O B$ & nest & $r \gamma$ & rylos & to build a nest (vi) \\
\hline$t r-$ & $-r \not a \beta$ & woman & $n \gamma-$ & пrтақ $\beta$ & to marry (vt) \\
\hline$t r-$ & $-p r r i$ & dinner & $n \gamma-$ & nярягі & to have dinner (vi) \\
\hline$t \gamma-$ & $-p r r i$ & dinner & $n \gamma-$ & nrprri & to have dinner (vi) \\
\hline \multirow[t]{2}{*}{ tr- } & $-r m i$ & name & $s \gamma-$ & srrmi & to give a name (vt) \\
\hline & 6om & skin of the milk & $r \gamma-$ & $r \gamma-60 m$ & to have a skin (of milk) (vi) \\
\hline tul- & $-n u$ & breast & nuI- & пипиш & to suck (vt) \\
\hline \multirow[t]{3}{*}{ tul- } & $-6 t s i$ & sweat & sul- & sulctsi & to cause to sweat (vt) \\
\hline & ftcrka & method & rut- & ruftcrka & to prepare (vi) \\
\hline & $t s^{h} a$ & tea & nu- & nuuts ${ }^{h} a$ & to have breakfast (vi) \\
\hline
\end{tabular}

Exceptions to the vowel copying principle between indefinite possessor and denominal verb can be found: there are examples of inalienably possessed nouns with tu- indefinite possessor whose denominal verbs have $\gamma$ vocalism $^{22}$, but the reverse is not true: there are no nouns in $t \gamma$ - with denominal verbs in $u$.

Action nominal prefixes can be preserved after denominal derivation, as shown in table $16 .^{23}$

Table 16: Action nominal tu-prefix preserved after denominal derivation

\begin{tabular}{llllll}
\hline Base verb & Meaning & Action nominal & Meaning & Denominal verb & Meaning \\
\hline$f_{6} r l$ & have diarrhoea (vi) & $t_{u-f_{\varphi} r l}$ & diarrhoea & nu- $t u-f_{\varphi} r l$ & have diarrhoea (vi) \\
$s_{q a}$ & to cook (vt) & $t_{u-s q a}$ & wheat porridge & rut-tu-sqa & have wheat porridge \\
\hline
\end{tabular}

\subsubsection{Denominal $r r-$ prefix}

The denominal $r u-/ r \gamma$ - prefix is very productive, and generally used to derive intransitive verbs out of a noun. Verbs derived with this prefix can refer to the production of the entity designated by the base noun either by active building (as in the example 'make a nest' in table 17) or by spontaneous effect ('to have a skin'). In a few cases, $r u-/ r \gamma$ - can be used to derive a verb meaning 'becoming NOUN' (as in 'to become a nun'). Finally, it can derive either transitive or intransitive verbs whose meaning is to perform the activity referred to by the base noun ('harvest' $\rightarrow$ 'to harvest').

\footnotetext{
${ }^{22}$ For instance - $-\gamma m r r$ 'mouth' has the indefinite possessor prefix $t u$ - but its denominal verb is $n \gamma$-ymrr' to hold in the mouth')

${ }^{23}$ Although both nutuf $f \gamma l$ and $f_{6} \gamma l$ are translated by the same English gloss, their meanings are different. The first one has human $S$, while the second must have the body part inalienably possessed noun $-x t u$ 'belly' as its only possible argument.
} 
Table 17: Examples of denominal verbs in $r u-$ and $r \gamma$ - in Japhug (inalienably possessed nouns are indicated with their indefinite possessive prefix $t \gamma-/ t u$ - and the quantifier nouns with the numeral one $t u$ - between brackets)

\begin{tabular}{|c|c|c|c|c|c|}
\hline Category & Transitivity & Derived verb & Meaning & Base noun & Meaning \\
\hline \multirow[t]{4}{*}{ inalienable } & intr. & $r \gamma-r f i t$ & to have a child & $(t \gamma)-r f i t$ & child \\
\hline & intr. & ru-tсrmu & to become a nun & tсrmu & nun \\
\hline & intr. & ruu-qarts $\gamma \beta$ & to harvest & qarts $\gamma \beta$ & harvest \\
\hline & intr. & $r \gamma-z g a$ & to make honey & $z g a$ & sauce (cf $\gamma \not \gamma-z g a$ 'honey') \\
\hline \multirow[t]{2}{*}{ inalienable } & intr. & rui-suso & to think & (tu)-suiso & thought, desire \\
\hline & intr. & $r \gamma-p є а в$ & to prostrate oneself & рсав & prostration \\
\hline inalienable & tr. & $r \gamma-p j \gamma z$ & to plait & $(t r)-p j r z$ & plait \\
\hline quantifier & tr. & $r \gamma$-spra & to take a handful of & (tuu)-spra & one handful \\
\hline
\end{tabular}

The distribution of the allomorphs $r u-/ r \gamma$-generally follow the rules presented in the previous section. Inalienably possessed nouns with $t \gamma$ indefinite possessor and quantifier nouns always have a denominal verb in $r$ r-; inalienably possessed nouns and other nouns can have either ru- or $r \gamma-$

Table 18: Types of denominal verbs in $r u-$ and $r \gamma$ - in Japhug

\begin{tabular}{llll}
\hline Form & Category & Transitivity & Number of examples \\
\hline$r u-$ & production & intr. & 2 \\
$r \gamma-$ & production & intr. & 9 \\
$r u-$ & becoming & intr. & 1 \\
$r \gamma-$ & becoming & intr. & 1 \\
$r u-$ & perform activity & intr. & 9 \\
$r \gamma-$ & perform activity & intr. & 3 \\
$r u-$ & perform activity & tr. & 2 \\
$r \gamma-$ & perform activity & tr. & 4 \\
\hline
\end{tabular}

Table 18 provides a complete list of types of denominal verbs in ru- or $r \gamma$ - From this list, it appears that transitive verbs are less common than intransitive ones ( 5 out of 25), and among these transitive verbs three are derived specifically from quantifier nouns such as tu-spra 'one handful'.

The prefix $r u-/ r \gamma$ - is extremely productive and can be applied to Chinese loanwords, in which case it always derives an intransitive verb. There are no other derivational prefixes $r \boldsymbol{r}$ - or $r u$ - in Japhug.

\subsubsection{Denominal $s \gamma$ - prefixes}

The denominal verbs in $s u-/ s \gamma$ - can be either transitive or intransitive, and belong to four semantic categories: property, position, use of an instrument or body part, and causative, as presented in table 19. 
Table 19: Examples of denominal verbs in $s u-$ and $s \gamma$ - in Japhug

\begin{tabular}{|c|c|c|c|c|c|}
\hline Category & Transitivity & Derived verb & Meaning & Base noun & Meaning \\
\hline property & $\begin{array}{l}\text { intr. } \\
\text { intr. }\end{array}$ & $\begin{array}{l}\text { sr-ndry } \\
\text { sr-mbruI }\end{array}$ & $\begin{array}{l}\text { to be poisonous } \\
\text { to be angry }\end{array}$ & $\begin{array}{l}\text { (tr)-ndrr } \\
(t \gamma)-m b r u z\end{array}$ & $\begin{array}{l}\text { poison } \\
\text { anger }\end{array}$ \\
\hline position & intr. & su-ndzupe & to sit (in a special way) & ndzupe & way of sitting \\
\hline $\begin{array}{l}\text { instrument } \\
\text { instrument }\end{array}$ & $\begin{array}{l}\text { intr. } \\
\text { tr. }\end{array}$ & 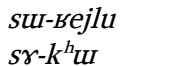 & $\begin{array}{l}\text { be left-handed } \\
\text { to smoke }\end{array}$ & $\begin{array}{l}\text { sejlu } \\
(t \gamma)-k^{h} u I\end{array}$ & $\begin{array}{l}\text { left hand } \\
\text { smoke }\end{array}$ \\
\hline instrument & tr. & sur-fsay & $\begin{array}{l}\text { to perform } \\
\text { ritual fumigation }\end{array}$ & fsay & fumigation \\
\hline instrument & tr. & sury-ts ${ }^{h} a b$ & to sieve & $t s^{h} a b$ & sieve \\
\hline causative & tr. & suI- GtSi & to cause to sweat & $(t u)-\epsilon t s i$ & sweat \\
\hline causative & tr. & $s \gamma-r m i$ & to give a name & $(t \gamma)-r m i$ & name \\
\hline
\end{tabular}

The total count of examples in each category of the $s u-/ s \gamma$-denominal derivation in our forthcoming dictionary is listed in table $20 .^{24}$

Table 20: Types of denominal verbs in $s u-$ and $s \gamma$ - in Japhug

\begin{tabular}{|c|c|c|c|}
\hline Form & Category & Transitivity & Number of examples \\
\hline$s \gamma-$ & property / mental state & intr. & 4 \\
\hline sUt & position & intr. & 2 \\
\hline sut- & use of an instrument / body part & intr. & 1 \\
\hline sut & use of an instrument / body part & labile & 2 \\
\hline SUI- & use of an instrument / body part & tr. & 6 \\
\hline sury- & use of an instrument / body part & tr. & 3 \\
\hline$s \gamma-/ s a-$ & use of an instrument / body part & tr. & 3 \\
\hline sut- & causative & tr. & 2 \\
\hline$s \gamma$ & causative & tr. & 1 \\
\hline
\end{tabular}

The intransitive verb $s \gamma$-mbru 'to become angry' derived from the possessed noun $t \gamma$-mbru 'anger' has an irregular causative form $s \gamma$-z-mbruI 'to anger', with the causative prefix $-z$ - inserted between the denominal prefix and the root. This causative form is highly regular and isolated, and constitutes an exception to the template presented in Table 12.

Apart from its denominal use, $s \gamma$ - can derive transitive verbs out of ideophones. ${ }^{25}$ For instance, out of the ideophone $1 t s^{h} \gamma l t{ }^{h} \gamma t$ 'slightly vibrating (as hair, small threads)' (basic root $1 t s^{h} \gamma t$ ), one can derive the transitive verb $s \gamma-1 t s^{h} \gamma l t s^{h} \gamma t$ 'to shake slightly'. This derivational process is extremely productive.

Additionally, we find two other homophonous prefixes. One simply results from the fusion of the causative $s u$ - with the passive $a-$ and will not concern us here ( $m b i$ 'to give', $j t s^{h} i$ 'to give to drink' $\rightarrow s u I-\gamma-m b i$ 'to

\footnotetext{
${ }^{24}$ These figures slightly differ from those presented in Jacques (2012c), as more examples have been found during recent fieldwork.

${ }^{25}$ This phenomenon has been first described in the related Tshobdun languages by Sun and Shidanluo (2004).
} 
ask to be given something', sul- $\gamma-j t s^{h} i$ 'to ask for something to drink').

The other $s \gamma$ - prefix, the de-experiencer, derives a stative verb out of an intransitive or a transitive verb. When applied to an intransitive verb, the $S$ of the base verb is deleted and replaced by the stimulus. For instance, from the intransitive verbs ngio 'to slip', scit 'to be happy ' which can have a human S, one derives $s \gamma$-ngio 'to be slippery' (of the ground) and $s \gamma$-scit 'to be nice' (of an environment, situation). In the case of transitive verbs, the $\mathrm{S}$ of the de-experiencer verb corresponds to the $\mathrm{O}$ of the base verb (cf. Jacques 2012b). ${ }^{26}$

We will see in section 4.2 how the human antipassive, the denominal $s \gamma-$ and the de-experiencer are relatable historically.

\subsection{Phonotactic constraints on derivational prefixes}

In Japhug, derivational prefixes present important phonological constraints, limiting the number of possible forms. These prefixes are either mono- or disyllabic, the possible vowels are $u, \gamma$ and more rarely $a$, and out of the 49 consonant phonemes, only nine $\left(\mathrm{m} \mathrm{n} \mathrm{r} \mathrm{s} / \mathrm{z}_{6} / \mathrm{h} \mathrm{j}_{\mathrm{\gamma}}\right)^{27}$ are found in verbal derivational prefixes.

These strong phonotactic constraints suggest that, whatever the historical origin of these prefixes, they have undergone phonetic attrition and a series of mergers specific to the prefixal position that may have blurred their historical origin.

Thus, the mere fact that two prefixes share a common pronunciation and related semantics is not sufficient to prove that they are historically related, as the probability of chance resemblances is too high. In the following section, we will therefore focus on irregular derivations, as irregularities are the most efficient tool to test historical hypotheses (Schindler 1972).

\section{Evidence for the denominal origin of the antipas- sive prefixes}

As presented in the introduction of this paper, several origins have been documented for antipassive markers cross-linguistically: reflexive, reciprocal, indefinitive person, and light verbs. It appears that none of these can explain the origin of Japhug antipassive markers in a straightforward way. Japhug has specialized and productive reflexive (the $z \gamma^{\gamma}$ - prefix, see

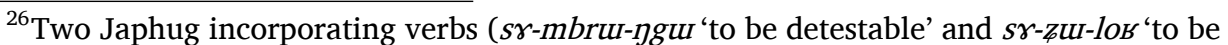
disgusting') also include the de-experiencer prefix $s \gamma$-. The exact pathway of derivation of these two verbs is described in detail in Jacques (2012c: §4.1).

${ }^{27}$ We could reduce this figure to seven, since the voiced fricatives $/ \mathrm{z} /$ and $/ \mathrm{z} /$ and their voiceless counterparts $/ 6 /$ and $/ \mathrm{s} /$ are never contrastive in prefixes, and their distribution is always predictable. Two more consonants $(/ \mathrm{t} /$ and $/ \mathrm{k} /$ ) appear in non-finite verbal prefixes.
} 
Jacques 2010b) and reciprocal (the $a$ - prefix with reduplication of the last syllable of the verb stem) constructions, and none bear any phonetic resemblance to the antipassive prefixes. As for indefinite person, Japhug has a dedicated generic construction (with ergative alignment $k u-$ prefix for S/O and $w \gamma$ - for A, see Jacques 2012b) and an indefinite determiner $c i$, none of which has any similarity with the antipassive forms.

Finally, although examples of verbal prefixes originating from verbs have been documented in Japhug (in particular the associated motion prefixes, see Jacques 2013), of all the light verbs found in the Rgyalrong languages, none bears any similarity to the antipassive markers. ${ }^{28}$

On the other hand, we have shown that both antipassive markers are phonetically similar to denominal prefixes. This surface resemblance, though not conclusive by itself, is at least a necessary preliminary condition to investigating whether the two sets of prefixes (antipassive and denominal) can be related.

The following hypothetical derivation path in two stages can be proposed to account for the relationship between these prefixes:

1. A transitive verb is nominalized into an action nominal.

2. The action nominal is turned into a verb by a denominal construction deriving intransitive verbs.

Thus, although in this hypothesis antipassive prefixes do not originate from light verbs, this scenario is in fact very similar to that proposed for West Greenlandic and Mande.

An equivalent of stage 1 was present in West Greenlandic, since all three antipassive suffixes originate from the fusion of a nominalization / participial suffix followed by a verb. In Mande, no such stage can be detected, but this is probably due to the fact that these languages allow zero derivation between noun and verbs.

Stage 2 corresponds to the use of a verb meaning 'make' or 'get' in Mande and Eskimo, which are in these cases periphrastic denominal constructions, but can be applied to affixal denominal constructions such as those found in Japhug.

Japhug would thus only differ from the West Greenlandic situation in that the denominal markers cannot be etymologized as coming from verbs.

In the following sections, we evaluate whether this scenario is applicable to the case of Japhug. We first discuss the status of action nominalization in Japhug (the intermediate stage of the hypothesized grammaticalization pathway), and then present several idiosyncrasies which would be unexplainable without the grammaticalization scenario outlined above.

\footnotetext{
${ }^{28}$ In Japhug the common light verbs are the following: $1 \gamma t$ 'to throw', $\beta z u$ 'to do', $p a$ 'to do' and $t i$ 'to say'.
} 


\subsection{Non-human antipassive}

In Japhug, as seen in section 2.2, almost all deverbal nouns are marked with a specific derivational prefix, and thus any denominal derivation should preserve the nominalization prefix. This is indeed verified for cases such as nukumas 'to be wrong (vi)', a denominal verb derived from ku-mas 'which is not', the S-nominal of mas 'not to be' as well as the verbs in Table 16. It is clear that the antipassive prefixes $r \gamma$ - and $s \gamma$-cannot have originated from such nominalized forms.

Nevertheless, in section 2.2.3, we saw that a few nominalized forms are simply formed by converting the bare verbal stem to inalienably possessed nouns, always taking possessive prefixes (bare infinitives and bare action nominals).

Thus, the antipassive $r \gamma-\epsilon p^{h} \gamma t$ 'to patch clothes' of the transitive verb $\epsilon p^{h} \gamma t$ is actually synchronically ambiguous. It could be perfectly well analysed as the denominal derivation in $r \gamma$ - from the inalienably possessed $-6 p^{h} \gamma t$ 'patch', the bare action nominal derived from $\varphi p^{h} \gamma t$.

That this analysis is indeed possible is confirmed by the fact that the only bare action nominal whose indefinite possessive prefix is tul- (not tr-), -suso 'thought', has a derived denominal verb rususso 'to think (vi)' in $\mathrm{rut}-{ }^{29}$

From both the point of view of phonology and semantics, it is possible to assume that the denominal prefix $r y$ - arose from a development in two stages:

1. Transitive verb $\rightarrow$ bare action nominal ( $6 p^{h} \gamma t$ 'to patch (vt)' $\rightarrow-6 p^{h} \gamma t$ 'patch (n)')

2. bare action nominal $\rightarrow$ intransitive denominal verb $r \gamma-\epsilon p^{h} \gamma t^{\prime}$ to patch clothes'

It is not necessary to assume that a derivation in several stages occurred for all antipassive verbs. It suffices to have a critical mass of ambiguous pivot forms such as $r \gamma-\varphi p^{h} \gamma t$ for the prefix $r \gamma$ - to undergo reanalysis from denominal to antipassive. After reanalysis took place, the two prefixes became entirely distinct, and they do not even belong to the same slot in the verbal template in Japhug as spoken today, as we saw in section 3.1.

Any historical hypothesis must not only account for regular development, but should also provide an account for irregularities. In the following, we show that some common irregularities between action nominals and antipassive verbs can be explained by a series of stages involving nominalization followed by denominal derivation.

\footnotetext{
${ }^{29}$ We saw in section 3.3.1 that inalienably possessed nouns whose indefinite possessive prefix is $t u$ - generally make their denominal verbs in $r u-$ while those in $t \gamma$ - always have denominal verbs in $r r$ -
} 


\subsubsection{Irregular phonology}

As seen in section 3.3.2, only two antipassive verbs have a phonologically irregular form, one for which is $r \gamma$-nja "to owe money" from the verb $n a$ 'to buy on credit, to owe'.

The transitive verb ga takes as its object the amount of money owed (not the person to whom the money is owed):

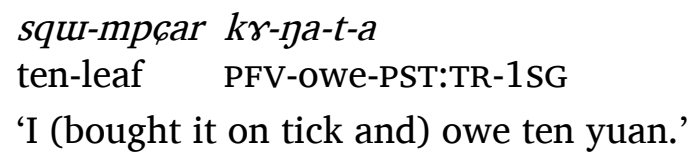

With the antipassive $r \gamma$-nna, the amount owed cannot be specified. The antipassive form is irregular in that an extra element $n$ - appears between the antipassive prefix and the verb root. It is noteworthy that the inalienably possessed noun -nna 'debt' has the same irregularity as the antipassive form. In section 2.2.2, we saw that this $n$ - is an irregular allomorph of the action nominalization prefix $t u-$ with irregular syncope $(-n \eta a<* t \eta a)$.

The indefinite possessive prefix associated with -nja is tur-(thus tur-nga 'someone's debt'), but we saw in section 3.3.1 that inalienably possessed nouns form their denominal verbs with either the $u$ or the $r$ allomorph of the denominal prefixes. Thus, $r \gamma$-nna 'owe a debt' is a possible outcome for the denominal derivation of $-n \eta a$ 'debt'. Just like $r \gamma-\varphi p^{h} \gamma t$ 'to patch clothes' above, it is a synchronically ambiguous form.

While in the case of $r \gamma-\varphi p^{h} \gamma t$ 'patch clothes' one could argue that the resemblance between the antipassive marker $r \gamma$ - and the intransitive denominal prefix is fortuitous, this option is not available in the case of $r \gamma-n \eta a$ 'to owe a debt'. The common irregularity between the nominal form -nna 'debt' and the verb $r \gamma$-nna 'to owe a debt' shows that $r \gamma$-nna cannot have been directly derived from the base verb na 'to owe', and that the inalienably possessed noun -nja 'debt' was the intermediate stage of derivation.

Unlike $r \gamma-6 p^{h} \gamma t$ 'to patch clothes' above, the pathway of derivation occurred in three stages:

1. நa 'to owe' $\rightarrow$ action nominal *tu- நa 'debt'

2. conversion into an inalienably possessed noun with syncope of the prefix vowel *tu-na $\rightarrow$ * $-t-\eta j a \rightarrow-n \eta$ a '(someone's) debt'

3. denominal derivation from the inalienably possessed nominal into an intransitive verb $-n \eta a \rightarrow r \gamma$-nпa 'to owe a debt'

This example shows that while the basic scenario ACTION NOMINALIZATION + INTRANSITIVE DENOMINAL DERIVATION for the origin of the Japhug antipassive accounts for the observed data, the bare action nominals in $t \gamma$ - are not necessarily the only intermediate nominalized stage of this grammaticalization pathway. 


\subsubsection{Irregular semantics}

The transitive verb руав 'to turn around' has an antipassive $r \gamma$-руав 'to reclaim land' which is not irregular phonologically like the previous example, but has semantics which are much more restricted than that of the base verb.

The irregular semantics, here again, is not specific to the antipassive form: it is shared with the action nominal tuा-руав which means 'land reclamation' and not 'turning over' as would be expected (cf section 2.2.2). This commonality shows that the action nominal and the antipassive form are related. Two hypotheses could be put forth to explain this common innovative meaning: either the antipassive is a denominal verb derived from the action nominal in $t u-$, or both the action nominal and the antipassive are linked to one another by a third form which was lost in the modern language. ${ }^{30}$

The first hypothesis, derivation from an action nominal in $t u-$, is problematic: as we saw in section 3.3.1, there are two examples of denominal verbs from action nominal, and they preserve the $t u$ - derivational prefix (tuu-sqa 'wheat porridge' $\rightarrow$ rul-tur-sqa 'to have wheat porridge', cf table 16). The expected denominal verb from tu-руав 'land reclamation' would thus be unattested †ru-tu-pуas instead of $r \gamma$-руав 'to reclaim land'.

The second hypothesis would imply the existence of a possessed noun *-руав 'reclamation of' (a particular place), from which $r \gamma$-pуав would be directly derived. This noun could simply be the bare infinitive derived from руав. we saw that a synchronic alternation between action nominals and bare infinitives is still productive in complements of the verb za 'to start' (see example 15, section 2.2.3).

We have shown that the $r \gamma$ - non-human antipassive in Japhug can be explained as originating from the reanalysis of the denominal prefix $r \gamma$ applied to inalienably possessed action nominals deriving from transitive verbs. Reanalysis occurred either from a bare action nominal, the bare infinitive or from an inalienably possessed nominal derived from the tur action nominals which underwent vowel loss and cluster coalescence.

The fact that this hypothesis explains common phonological and semantic irregularities between action nominals and antipassive verbs is a confirmation that the formal resemblance between the antipassive and the denominal prefixes is not a coincidence, but that the two constructions are historically related.

\footnotetext{
${ }^{30}$ The third possibility, namely a derivation from the antipassive to the action nominal, is impossible, as the derivational prefix $r \gamma$ - would not disappear.
} 


\subsection{Human antipassive}

In the previous section, we showed that the non-human antipassive $r \gamma$ prefix was historically derived from the denominal $r u-/ r \gamma$ - prefix. It is thus legitimate to attempt to apply the same explanatory model to the human $s \gamma$ - antipassive.

In section 3.3.1, we saw that a denominal prefix derives intransitive stative verbs designating an intrinsic property or mental state in examples such as $-n d r \gamma$ 'poison' $\rightarrow s r n d r \gamma$ 'to be poisonous'.

This derivation is semantically very close to the stative propensity antipassive described in 3. Using the same chain of derivation as for the $r \gamma$ antipassive, we propose the following scenario to explain the origin of the human antipassive in Japhug:

1. As in the case of the $r \gamma$ - antipassive, a transitive verb is turned into a inalienably possessed bare action nominal or a bare infinitive. (sat 'to kill' $\rightarrow-$ sat 'killing')

2. The action nominal undergoes denominal derivation with the prefix $s \gamma$ - into a property stative verb. (*-sat 'killing' $\rightarrow s \gamma$-sat 'to have a propensity to kill, to have killing power').

3. This stative verb is reanalyzed as an action verb due to some ambiguous contexts ( $s \gamma$-sat 'to have a propensity to kill' $\rightarrow s \gamma$-sat 'to kill people').

The de-experiencer $s \boldsymbol{\gamma}$-described in 3.3.3 can be explained as having undergone the same steps of reanalysis, except that the re-alignment of syntactic primitives occurred in a different way ( $\mathrm{S}=\mathrm{A}$ of base verb in the case of antipassive, $S=$ stimulus in the case of de-experiencer).

Unlike the case of the $r \gamma$ - antipassive, for the human antipassive we do not have any irregular verb showing shared idiosyncrasy between action nominal and human antipassive or de-experiencer as the examples discussed in sections 4.1.1 and 4.1.2. Thus, this hypothesis, while plausible, cannot be considered to be fully demonstrated until such an example is discovered.

\subsection{A chain shift?}

The presence of two antipassives in Japhug raises the question of how systems with human vs. non-human antipassive come into being. To our knowledge, only one case has been discussed in the literature, that of Nahuatl $t \bar{e}-$ 'human antipassive' (generally called 'indefinite human object') vs. tla- 'non-human antipassive' ('indefinite non-human object'). ${ }^{31}$ We will

\footnotetext{
${ }^{31}$ The analysis of these prefixes as antipassive markers has been proposed by Creissels (2006: 91).
} 
describe the Nahuatl data and then compare them with Japhug to evaluate whether the two languages attest the same type of evolution.

A detailed study on the etymology of the Nahuatl antipassive tla- and $t \bar{e}-$ prefixes is still lacking, but these prefixes have clear cognates in other languages and can be reconstructed to proto-Uto-Aztecan. Langacker (1977: 46) argues that the prefixes *ta- 'unspecified subject' and *ti- 'unspecified object' can be reconstructed in proto-Uto-Aztecan. The *ta- 'unspecified subject' prefix itself is probably related to the indefinite pronoun *hita 'something' (Langacker 1977: 120).

In Nahuatl these prefixes yield *ta- $\rightarrow$ tla- 'non-human antipassive'32 and $t \bar{e}-$ 'human antipassive', with a chain (push) shift:

- GENERIC AGENT $\rightarrow$ NON-HUMAN ANTIPASSIVE

- ANTIPASSIVE $\rightarrow$ HUMAN ANTIPASSIVE

By contrast, there is no evidence in Japhug that such a chain shift took place. The difference of meaning observed in the two antipassives $r \gamma$ - and $s \gamma$ - directly reflects that of their corresponding original denominal prefixes $r u-/ r \gamma$ - (production / action) and $s \gamma$ - (property of the base noun to which humans can be susceptible).

The fact that secundative ditransitive verbs have an antipassive in $r \gamma$ instead of expected $s \gamma$ - (see section 3.2) does not imply that antipassive in $r \gamma$ - used to be the general antipassive, later superseded by $s \gamma$ - for monotransitive verbs. Rather, it is likely that it is due to homophony avoidance with the combination of the causative with the passive $s u-+a-\rightarrow s \gamma-$ which is found with this type of verbs (as in $m b i$ 'to give' $\rightarrow s u-\gamma-m b i$ 'to ask to be given'). Since this combination of derivational prefixes is not attested with monotransitive verbs, this homophony avoidance was limited to ditransitive verbs.

Thus, the model of evolution presented in Japhug enriches our knowledge of the possible origins of human vs. non-human antipassive systems, as the development attested in Japhug seems without clear parallel elsewhere.

\subsection{Other derivations}

The pathway of grammaticalization proposed in the previous sections to explain the origin of the antipassive prefixes can also potentially be applied to other voice markers, in particular the applicative nu- and causative surprefixes. In this paper, only the case of the applicative will be discussed in detail.

The applicative nu- can be illustrated by the examples in Table 21.

\footnotetext{
${ }^{32}$ By the application of Whorf's law $* t a \rightarrow t l a$.
} 
Table 21: Examples of the nut- applicative prefix

\begin{tabular}{llll}
\hline base verb & \multicolumn{3}{c}{ derived verb } \\
\hline mbyom & be hurried & nut-mbyom & look forward to, miss s.o. \\
nke & go on foot & nu- $\eta$ ke & look for \\
rga & like (vi) & nu-rga & like (vt) \\
\hline
\end{tabular}

We also find a denominal prefix nu- in Japhug, which mainly derives transitive verbs, as illustrated in table 22.

Table 22: Examples of the denominal prefix nu-

\begin{tabular}{|c|c|c|c|c|}
\hline Base noun & Meaning & Derived verb & Meaning & \\
\hline sya & rust & nut-sya & to be rusty & vi \\
\hline qafy & fish & nu-qafy & to fish & vi \\
\hline- -jgra & salary & nu-ngra & to receive a salary & vi \\
\hline$m t^{h} u$ & spell & $n u-m t^{h} u$ & to cast a spell & $\mathrm{vt}$ \\
\hline kujiju & oath & nu-kuјjй & to swear & $\mathrm{vt}$ \\
\hline mburlrn & plane & nu-mburlsn & to plane & $\mathrm{vt}$ \\
\hline smrn & medicine & nu-smrn & to treat & vt \\
\hline mkryur & necklace & nu-mkдуur & to wear as a necklace & vt \\
\hline sgra & enemy & пu-ьgra & to treat as an enemy & vt \\
\hline$-s k^{h} r u$ & body & nut-sk ruu & to be pregnant with & vt \\
\hline
\end{tabular}

Although a few intransitives derived by the prefix nut are attested, when a pair of transitive and intransitive verbs are derived from a single noun, the productive pattern is to have an intransitive verb in $r u-/ r \gamma$ - and a transitive one in $n u-$, as illustrated in table 23 with Tibetan loanwords. ${ }^{33}$

Table 23: Examples of pairs of denominal verbs

\begin{tabular}{|c|c|c|c|}
\hline Base noun & Meaning & Intransitive & Transitive \\
\hline $\begin{array}{l}\text { ftcrka } \\
k^{h} \text { ramba }\end{array}$ & $\begin{array}{l}\text { method } \\
\text { lie }\end{array}$ & $\begin{array}{l}\text { ru-ftcrka 'to prepare (vi)' } \\
\text { ru-k } k^{h} r a m b a \text { 'to tell lies (vi)' }\end{array}$ & $\begin{array}{l}\text { nu-ftcrka 'to prepare (vt)' } \\
n u-k^{h} r a m b a \text { 'to cheat (vt)' }\end{array}$ \\
\hline
\end{tabular}

It is therefore possible to propose that the applicative resulted from the reanalysis of a denominal derivation of an action nominal as in the case of the antipassive prefixes.

Indeed, the mechanism of reanalysis illustrated in this paper concerning the antipassive derivation appears to be a common, but poorly recog-

\footnotetext{
${ }^{33}$ Respectively from Tibetan btca.ka 'method' and $k^{h}$ ram.ba 'lie'.
} 
nized, grammaticalization path leading to various voice markers, including antipassive and applicative, but not restricted to these two. Languages with rich denominal derivation systems have the possibility of creating new voice markers by combining the appropriate nominalized form with a denominal marker.

\section{Conclusion}

The present paper contributes to the general theory of grammaticalization in documenting a previously unreported origin for voice markers. It shows that voice markers, in particular the antipassive but also potentially the applicative and other ones, can be formed historically out of a double derivation:

(31) NOMINALIZATION + DENOMINAL DERIVATION $\Rightarrow$ VOICE DERIVATION

More specifically:

(32) ACTION NOMINALIZATION of transitive verb + INTRANSITIVE DENOMINAL DERIVATION $\Rightarrow$ ANTIPASSIVE

(33) ACTION NOMINALIZATION of intransitive verb + TRANSITIVE DENOMINAL DERIVATION $\Rightarrow$ APPLICATIVE / CAUSATIVE

The reason for this derivation in two steps is that action nominalization first NEUTRALIZES the original transitivity of the verb root, and a new transitivity value is allocated by a specific denominal derivation.

\section{References}

Comrie, Bernard. 1976. The syntax of action nominalizations: a crosslanguage study. Lingua 40:177-201.

Cooreman, Ann. 1994. A functional typology of antipassives. In Voice: Form and Function, ed. Barbara Fox and Paul Hopper: 49-87. Amsterdam: Benjamins.

Creissels, Denis. 2006. Syntaxe générale, une introduction typologique, tome 2, la phrase. Paris: Hermes Science Publications.

Creissels, Denis. 2012. The origin of antipassive markers in West Mande languages. In 45th Annual Meeting of the Societas Linguistica Europaea. Stockholm. 
Creissels, Denis, and Sylvie Nouguier-Voisin. 2008. Valency-changing operations in Wolof and the notion of co-participation. In Reciprocal and Reflexives, Theoretical and typological explanations, ed. Ekkerhard König and Volker Gast: 289-305. Berlin, New York: Mouton de Gruyter.

Dixon, Robert W.M. 1994. Ergativity. Cambridge: Cambridge University Press.

Fortescue, Michael. 1996. West Greenlandic half-transitive affixes in a diachronic perspective. In Cultural and Social Research in Greenland 95/96, Essays in Honour of Robert Petersen, ed. Birgitte Jacobsen. Nuuk : Ilisimatusarfik/Atuakkiorfik.

Fortescue, Michael, Steven Jacobson, and Lawrence Kaplan. 2010. Comparative Eskimo Dictionary, with Aleut cognates. Fairbanks: Alaska Native Language Center.

Grimshaw, Jane. 1990. Argument Structure. MIT Press.

Haspelmath, Martin. 1990. The grammaticalization of passive morphology. Studies in Language 14.1:25-72.

Heath, Jeffrey. 1976. Antipassivization: A Functional Typology. Berkeley Linguistic Society 2:202-211.

Heine, Bernd, and Tania Kuteva. 2002. World Lexicon of Grammaticalization. Cambridge: Cambridge University Press.

Jacobson, Steven A. 1984. Yup'ik Eskimo Dictionary. Fairbanks: Alaska Native Language Center.

Jacques, Guillaume. 2004. Phonologie et morphologie du japhug (Rgyalrong). Doctoral Dissertation: Université Paris VII - Denis Diderot.

Jacques, Guillaume. 2010a. The inverse in Japhug Rgyalrong. Language and Linguistics 11.1:127-157.

Jacques, Guillaume. 2010b. The origin of the reflexive prefix in Rgyalrong languages. Bulletin of the School of Oriental and African studies 73.2:261268.

Jacques, Guillaume. 2012a. A new transcription system for Old and Classical Tibetan. Linguistics of the Tibeto-Burman Area 35.2:89-96.

Jacques, Guillaume. 2012b. Argument demotion in Japhug Rgyalrong. In Ergativity, Valency and Voice, ed. Katharina Haude and Gilles Authier: 199-226. Berlin: Mouton De Gruyter. 
Jacques, Guillaume. 2012c. From denominal derivation to incorporation. Lingua 122.11:1207-1231.

Jacques, Guillaume. 2013. Harmonization and disharmonization of affix ordering and basic word order. Linguistic Typology 17.2:187-217.

Janic, Katarzyna. 2013. Etude translinguistique de l'emploi antipassif de formes moyennes : étude comparative des langues slaves et des langues romanes. Doctoral Dissertation: Université Lyon 2.

Koptjevskaja-Tamm, Maria. 1993. Nominalizations. London: Routledge.

Langacker, Ronald W. 1977. An overview of Uto-Aztecan grammar: Studies in Uto-Aztecan grammar 1. Dallas: Summer Institute of Linguistics and the University of Texas at Arlington.

Malchukov, Andrej, Martin Haspelmath, and Bernard Comrie. 2010. Ditransitive constructions: a typological overview. In Studies in Ditransitive Constructions: A Comparative Handbook, ed. Andrej Malchukov, Martin Haspelmath, and Bernard Comrie: 1-64. Berlin: De Gruyter Mouton.

Michaud, Alexis. 2012. Monosyllabicization: patterns of evolution in Asian languages. In Monosyllables: from phonology to typology, ed. Thomas Stolz, Nicole Nau, and Cornelia Stroh: 115-130. Berlin: Akademie Verlag.

Mithun, Marianne. 2000. Valency-changing derivation in Central Alaskan Yup'ik. In Changing valency, Case studies in transitivity, ed. Robert M.W. Dixon and Alexandra Aikhenvald: 84-114. Cambridge: Cambridge University Press.

Nedjalkov, Vladimir P. 2007. Polysemy of reciprocal markers. In Reciprocal constructions, ed. Vladimir P. Nedjalkov: 231-334. Amsterdam: Benjamins.

Polinsky, Maria. 2011. Antipassive constructions. In The World Atlas of Language Structures Online, ed. Matthew S. Dryer and Martin Haspelmath: chapter 108. Munich: Max Planck Digital Library.

Say, Sergey S. 2008. K tipologii antipassivnyx konstrukcij: semantika, pragmatika, sintaksis. Doctoral Dissertation: Rossijskaja akademija nauk, Institut lingvisticheskix issledovanij, St-Petersburg.

Schindler, Jochem. 1972. L'apophonie des noms-racines indo-européens. Bulletin de la société linguistique de Paris 67:31-38.

Sun, Jackson T.-S. 1998. Nominal Morphology in Caodeng rGyalrong. Bulletin of the Institute of History and Philology 69.1:103-149. 
Sun, Jackson T.-S. 2003. Caodeng rGyalrong. In The Sino-Tibetan languages, ed. Graham Thurgood and Randy LaPolla: 490-502. London: Routledge.

Sun, Jackson T.-S. 2006. 嘉戎語動詞的派生形態 Jiāróngyǔ dòngcí de pàishēng xíngtài (Derivational morphology in the Rgyalrong verb). Minzu yuwen 民族語文 4.3:3-14.

Sun, Jackson T.-S., and Youjing Lin. 2007. Constructional Variation in rGyalrong Relativization: How To Make a Choice? In Pre-Conference Proceedings of the International Workshop on Relative Clauses: 205-226. Taipei: Institute of Linguistics, Academia Sinica.

Sun, Jackson T.-S., and Shidanluo. 2004. 草登嘉戎語的狀貌詞 Căodēng Jiāróngyǔ de zhuàngmàocí (The ideophones in Tshobdun Rgyalrong). Mínzú yǔwén 民族語文 5:1-11.

Tatevosov, S.K. 2004. Antipassiv kak aktsional'nyj modifikator: dannye godoberinskogo jazyka. In International symposium on typology of the argument structure and grammatical relations in languages spoken in Europe, North and Central Asia. Kazan'.

Terrill, Angela. 1997. The development of antipassive constructions in Australian languages. Australian Journal of Linguistics 17.1:71-88.

Thompson, Chad. 1996. On the grammar of body parts in Koyukon Athabaskan. In The Grammar of Inalienability: A Typological Perspective on Body Part Terms and the Part-Whole Relation, ed. Hilary Chappell and William McGregor: 651-677. Berlin, New York: Mouton de Gruyter.

Young, Robert W., and William Morgan. 1987. The Navajo Language, A Grammar and Colloquial Dictionary. Albuquerque: University of new Mexico Press. 